\title{
Flexibility Induced Encapsulation of Ultrafine Palladium Nanoparticles into Organic Cages for Tsuji-Trost Allylation
}

Vivekanand Sharma, ${ }^{a}$ Dinesh De, ${ }^{a}$ Ranajit Saha, ${ }^{b}$ Pratim Kumar Chattaraj, ${ }^{* b, c}$ and Parimal K. Bharadwaj*a

${ }^{a}$ Department of Chemistry, Indian Institute of Technology Kanpur, Kanpur 208016, India. E-mail: pkb@iitk.ac.in; Fax: +91-512-2597436; Tel: (+91) 512-259-7034.

${ }^{b}$ Department of Chemistry and Center for Theoretical Studies, Indian Institute of Technology Kharagpur, Kharagpur 721302, India.E-mail: pkc@chem.iitkgp.ac.in; Fax: +91-3222-255303; Tel: +91-3222-283304.

${ }^{\mathrm{c}}$ Department of Chemistry, Indian Institute of Technology Bombay, Mumbai, 400076, India 


\section{Instrumentation}

Powder X-ray diffraction (PXRD) patterns were recorded with a Bruker D8 Advance diffractometer equipped with nickel-filtered $\mathrm{Cu} \mathrm{K}_{\alpha}(1.5418 \AA)$ radiation. The tube voltage and current were $40 \mathrm{kV}$ and $40 \mathrm{~mA}$, respectively. ${ }^{1} \mathrm{H}$ NMR and ${ }^{13} \mathrm{C}$ NMR spectra were recorded on a JEOL ECS 400 FT $\left(400,100 \mathrm{MHz}\right.$ respectively) instrument in $\mathrm{CDCl}_{3}$ or in DMSO-d $d_{6}$ with $\mathrm{Me}_{4} \mathrm{Si}$ as the internal standard. The ESI-Mass data were obtained in a WATERS-Q-Tof Premier Mass Spectrometer. The MALDI-TOF has been performed on ABSCIEX, 4800 plus system. X-ray Photoelectron Spectroscopy (XPS) was performed using PHI 5000 Versa Prob II (FEI Inc.). TEM images and EDS have been taken from FEI Titan G2 60 -300 TEM (HR-TEM) and S2 FEI Tecnai G2 12 Twin TEM 120 kV. ICP-MS has been done with ICP-MS Thermo iCAP Q.

\section{Computational Details}

The $\boldsymbol{o}$-OC, $\boldsymbol{m}$-OC and $\boldsymbol{p}$-OC cages are modeled with Gaussview 5.0.9 software. Then we have optimized these cages using B3LYP (Becke, three-parameter, Lee-Yang-Parr) functional. ${ }^{1-2}$ The D3 version of Grimme's dispersion is used along with the B3LYP functional. ${ }^{3}$ Pople's 6-31G(d) ${ }^{4}$ basis set has been used for all atoms in this study. Thus, the full computational method can be written as B3LYP-D3/6-31G(d). Further the analytical Hessian matrix is determined by the frequency computations at the same level of theory. The presence of no imaginary frequency indicates that the optimized geometries are at the minima on their respective potential energy surfaces (PES). All of these computations are carried out using Gaussian16 program package. ${ }^{5}$ 


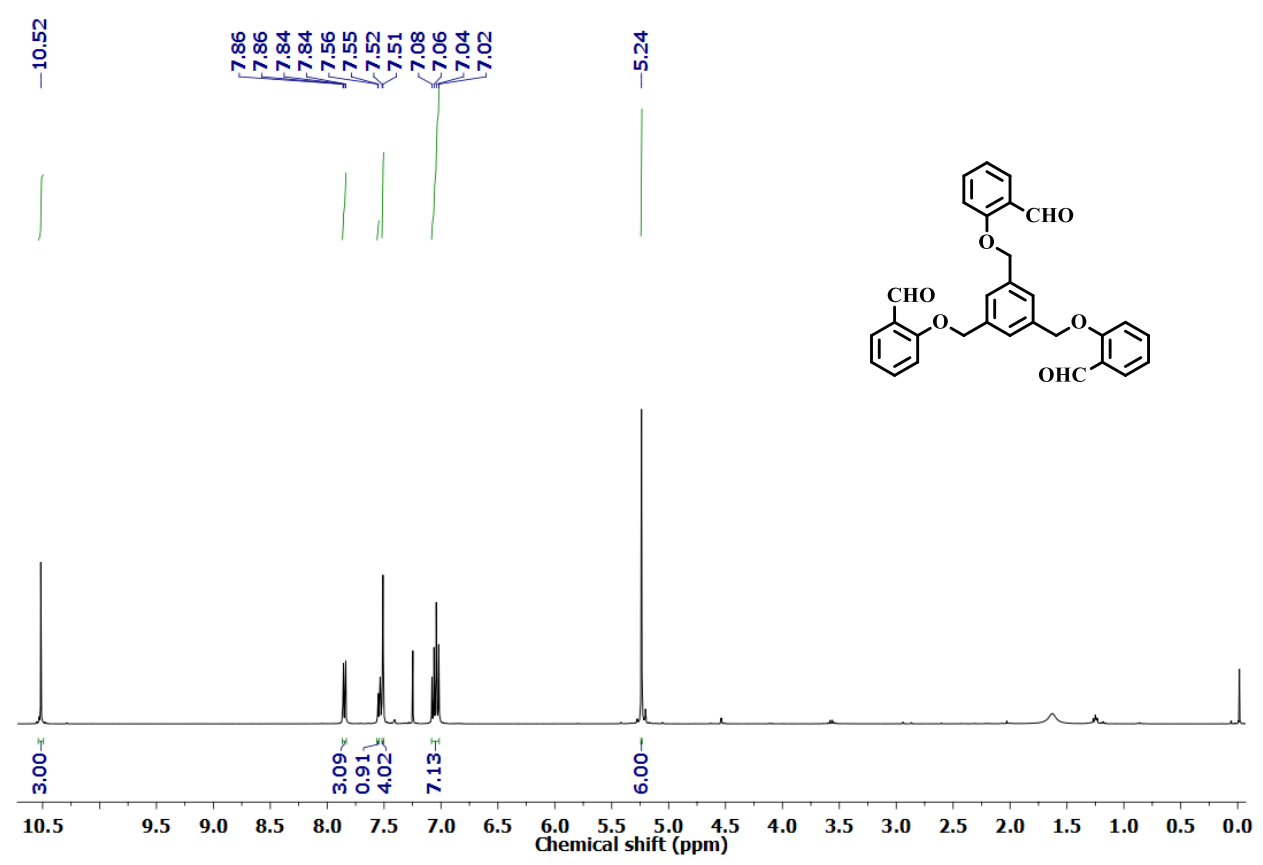

Figure S1. ${ }^{1} \mathrm{H}-\mathrm{NMR}$ of $\boldsymbol{o}$-TA

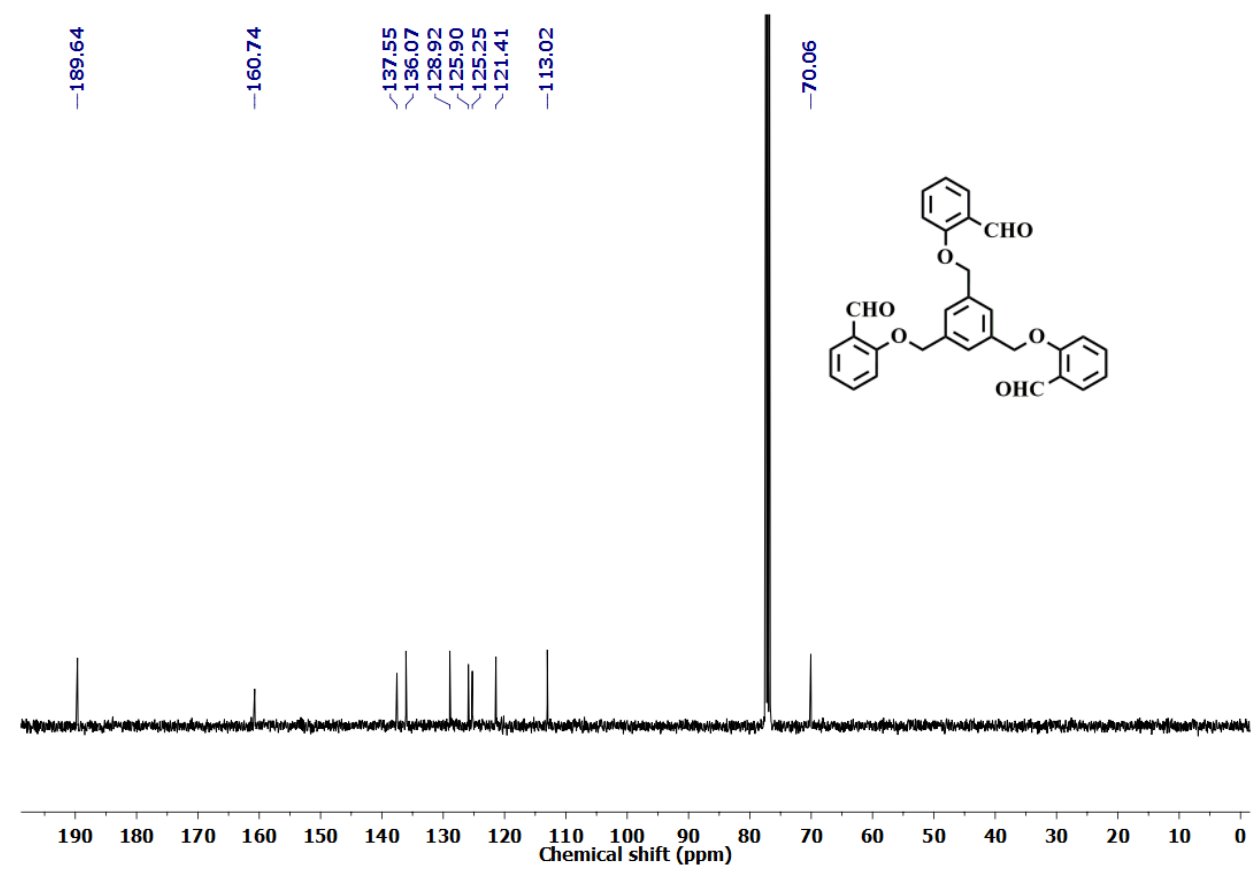

Figure S2. ${ }^{13} \mathrm{C}$ NMR of $\boldsymbol{o}$-TA 


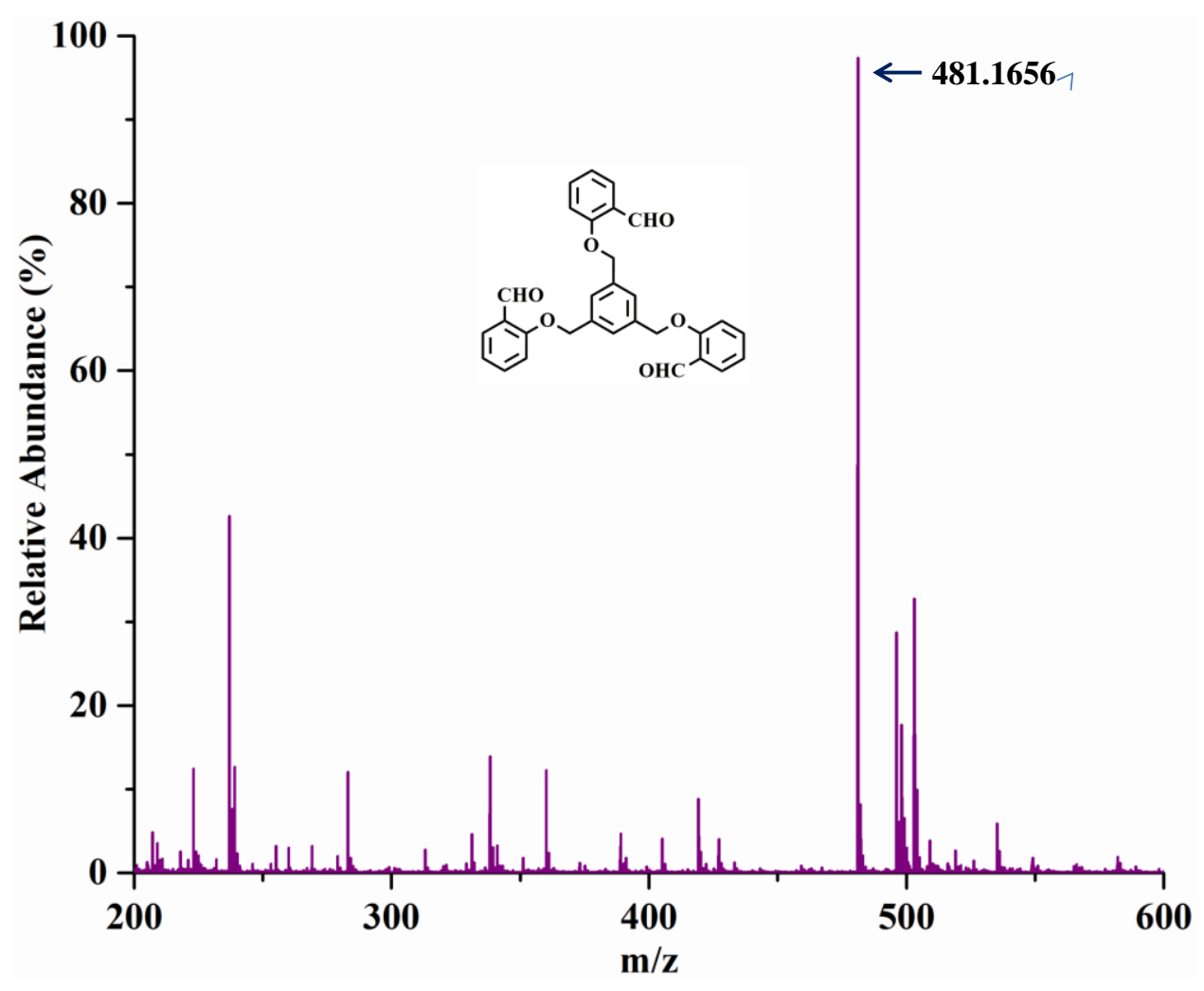

Figure S3. Mass Spectra of $\boldsymbol{o}$-TA

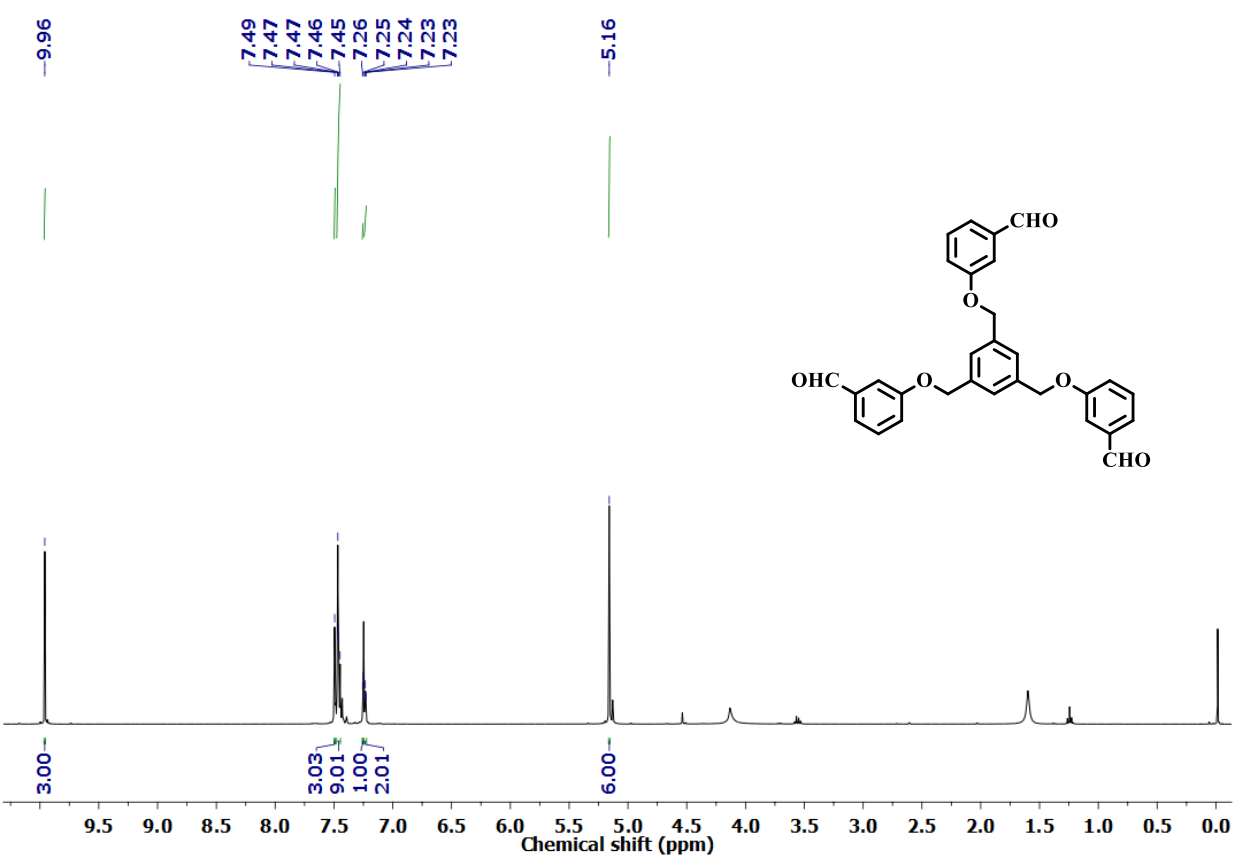

Figure S4. ${ }^{1} \mathrm{H}$ NMR of $\boldsymbol{m}$-TA 


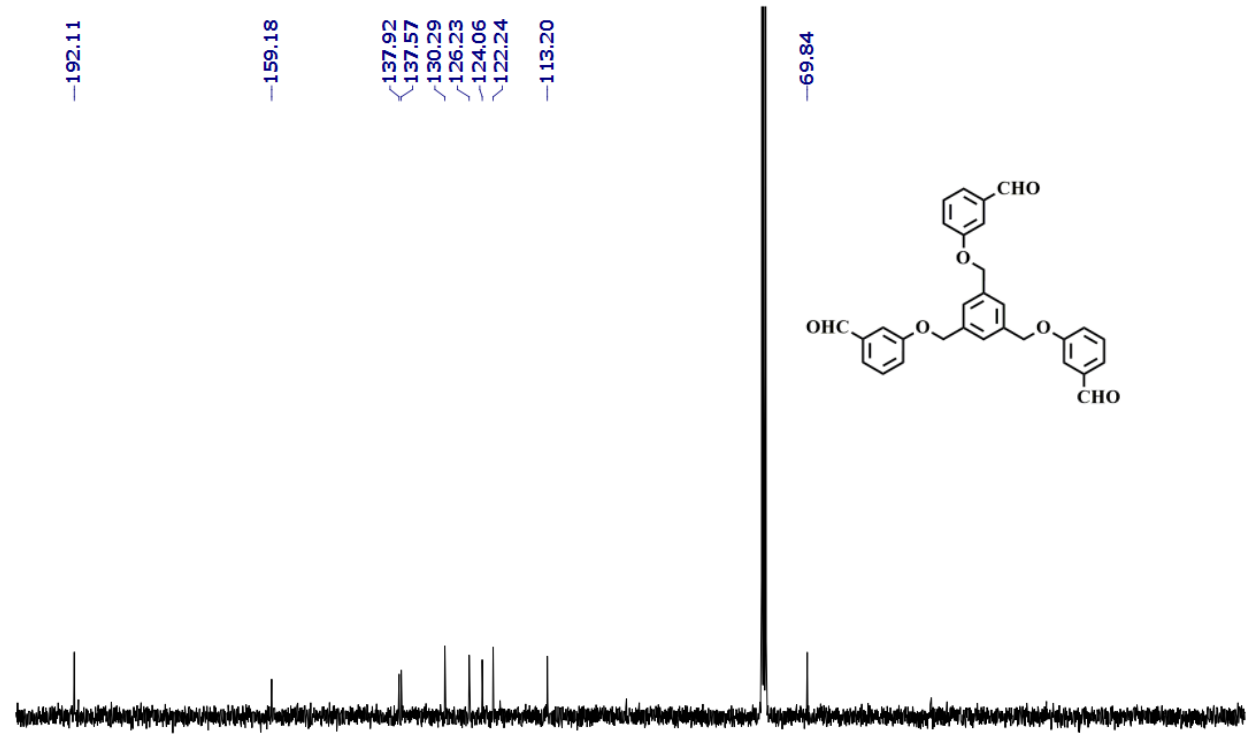

$\begin{array}{llllllllllllllllllll}200 & 190 & 180 & 170 & 160 & 150 & 140 & 130 & 120 & \begin{array}{c}110 \\ \text { Chemical shift } \underset{(\mathrm{ppm})}{90}\end{array} & 70 & 60 & 50 & 40 & 30 & 20 & 10 & 0\end{array}$

Figure S5. ${ }^{13} \mathrm{C}$ NMR of $\boldsymbol{m}$-TA

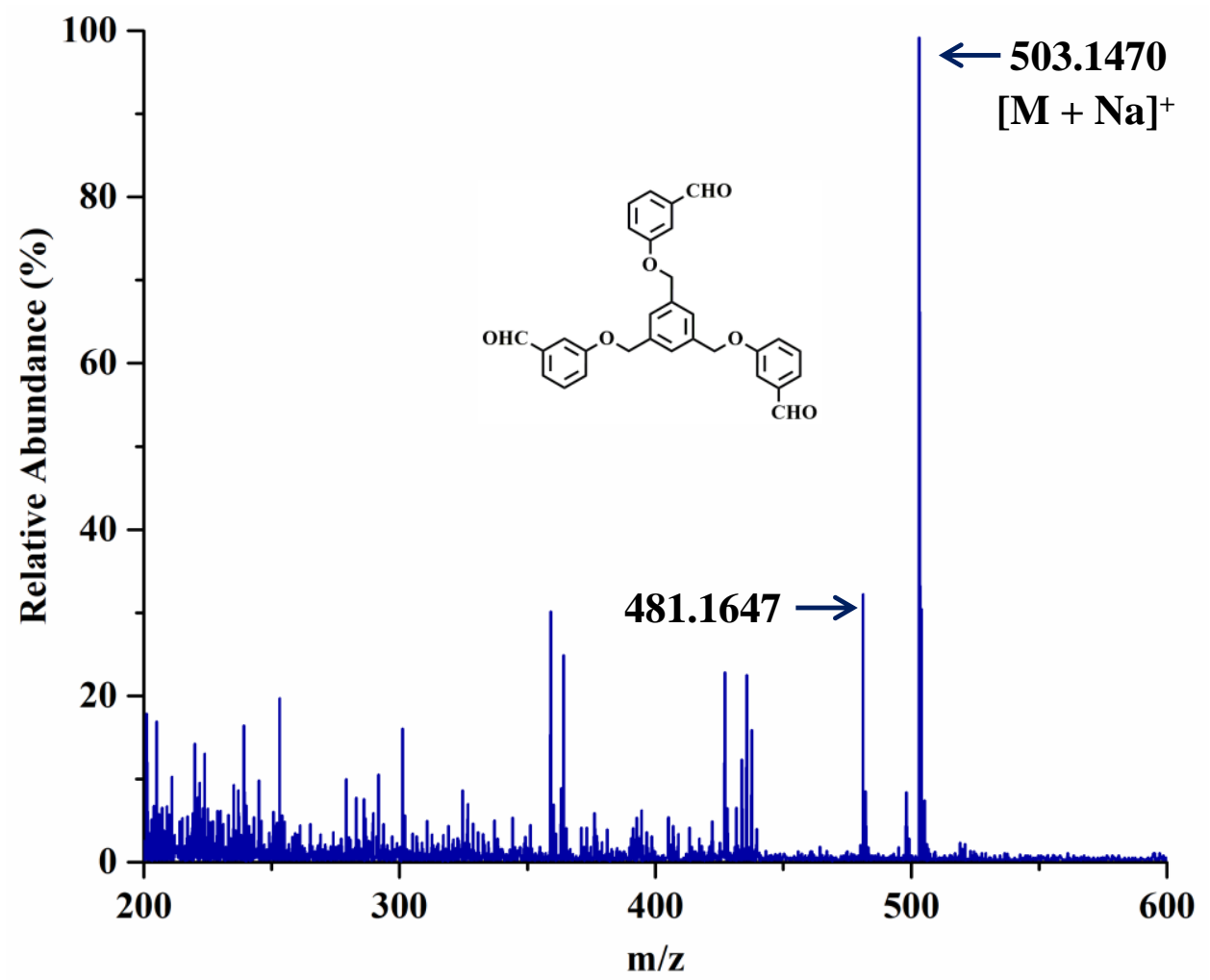

Figure S6. Mass Spectra of $\boldsymbol{m}$-TA 


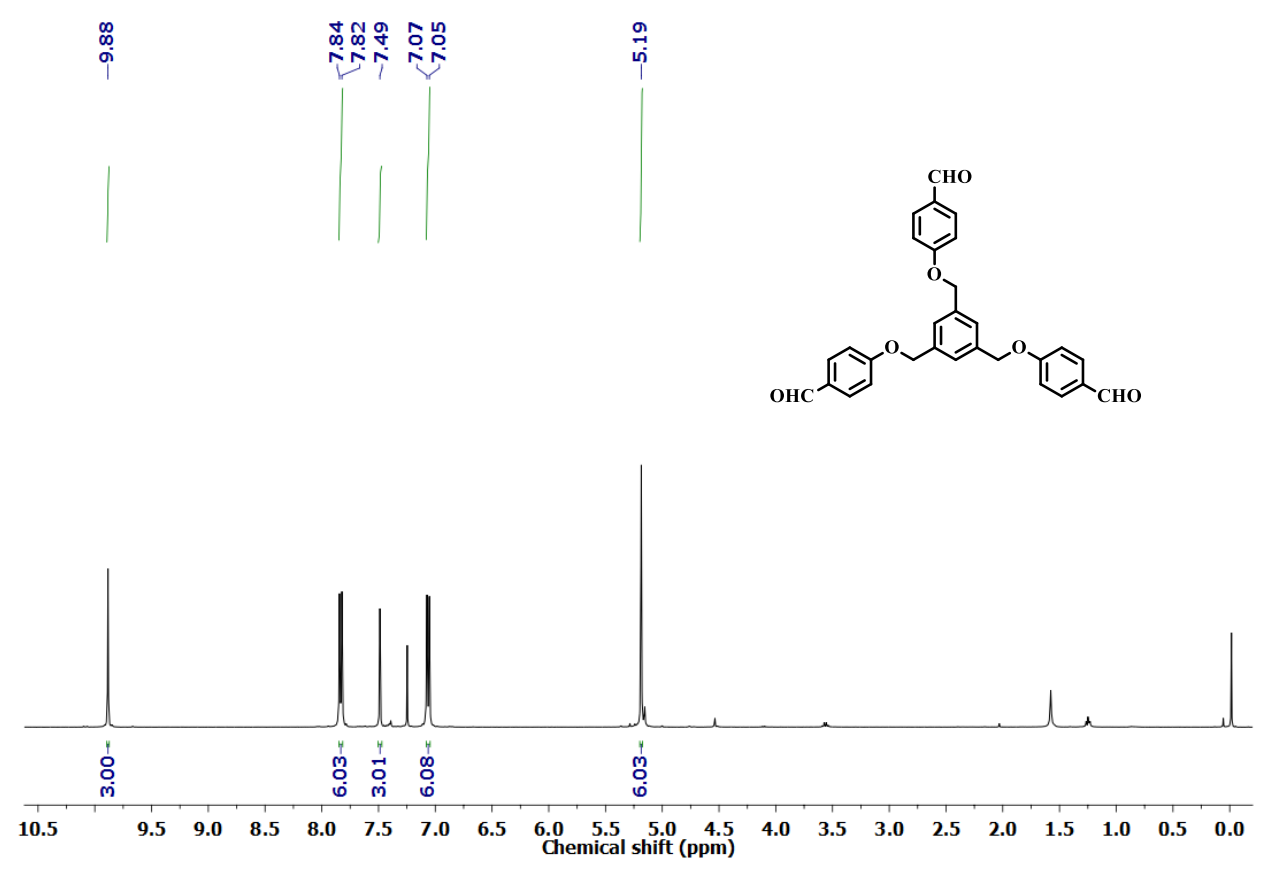

Figure S7. ${ }^{1} \mathrm{H}$ NMR of $\boldsymbol{p}$-TA
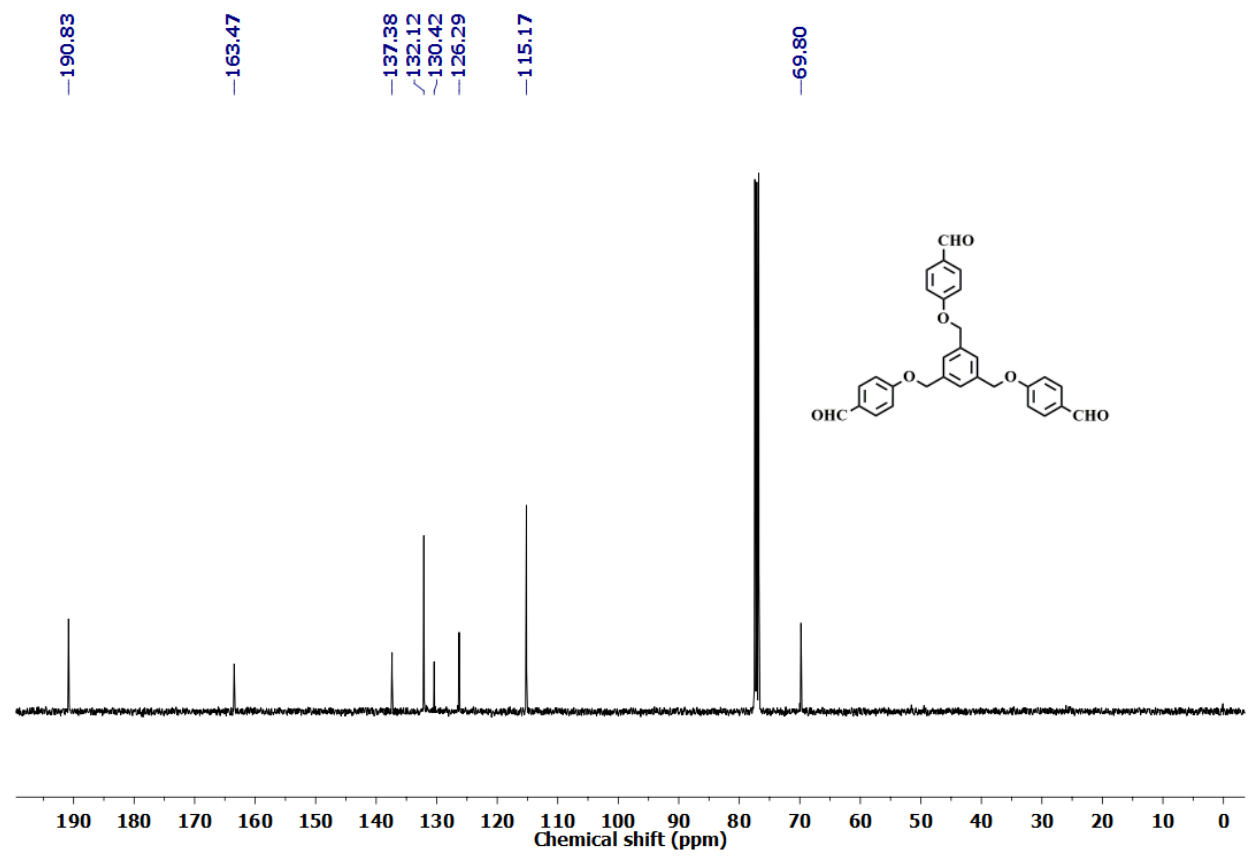

Figure S8. ${ }^{13} \mathrm{C}$ NMR of $\boldsymbol{p}$-TA. 


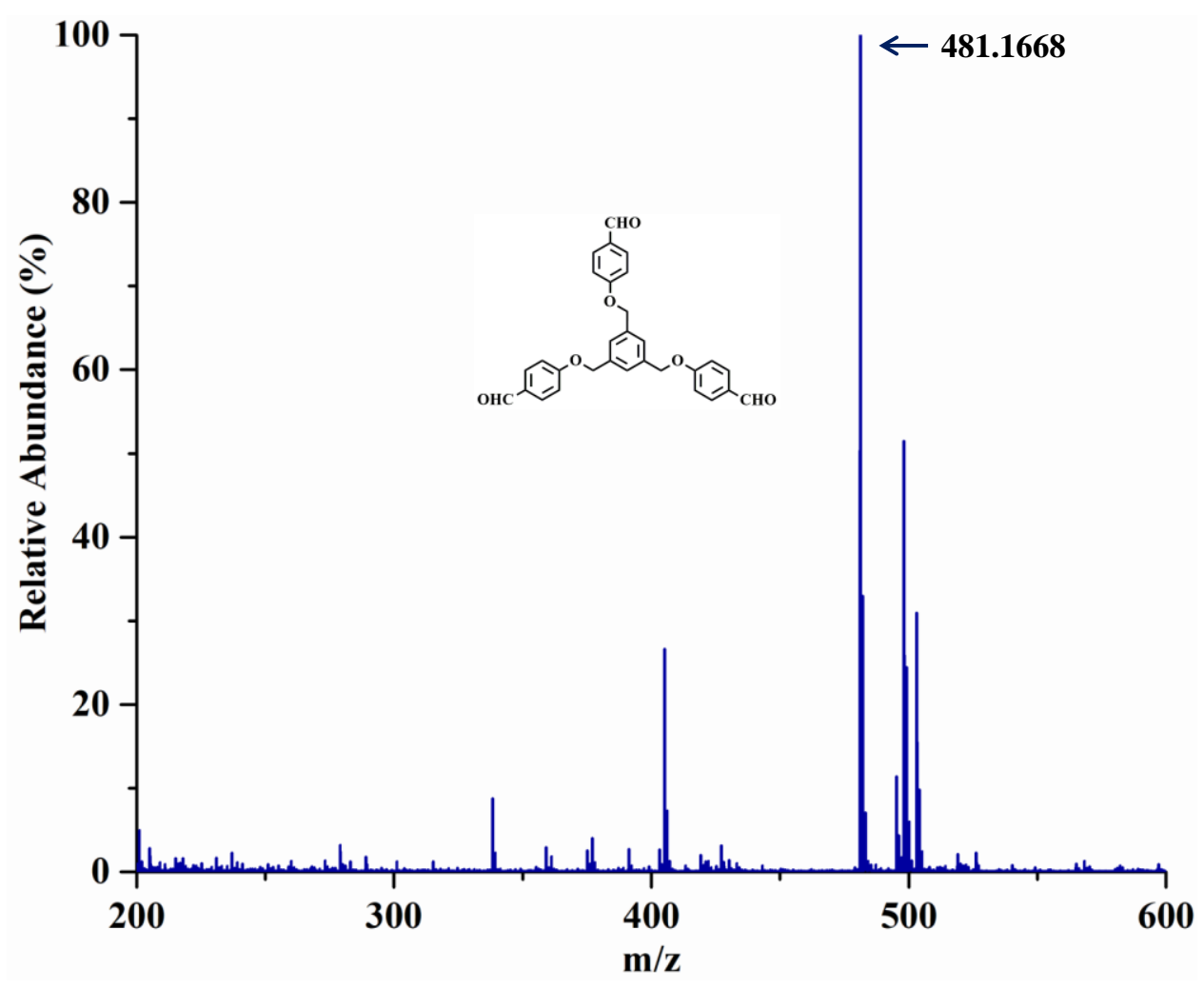

Figure S9. Mass spectrum of $\boldsymbol{p}$-TA

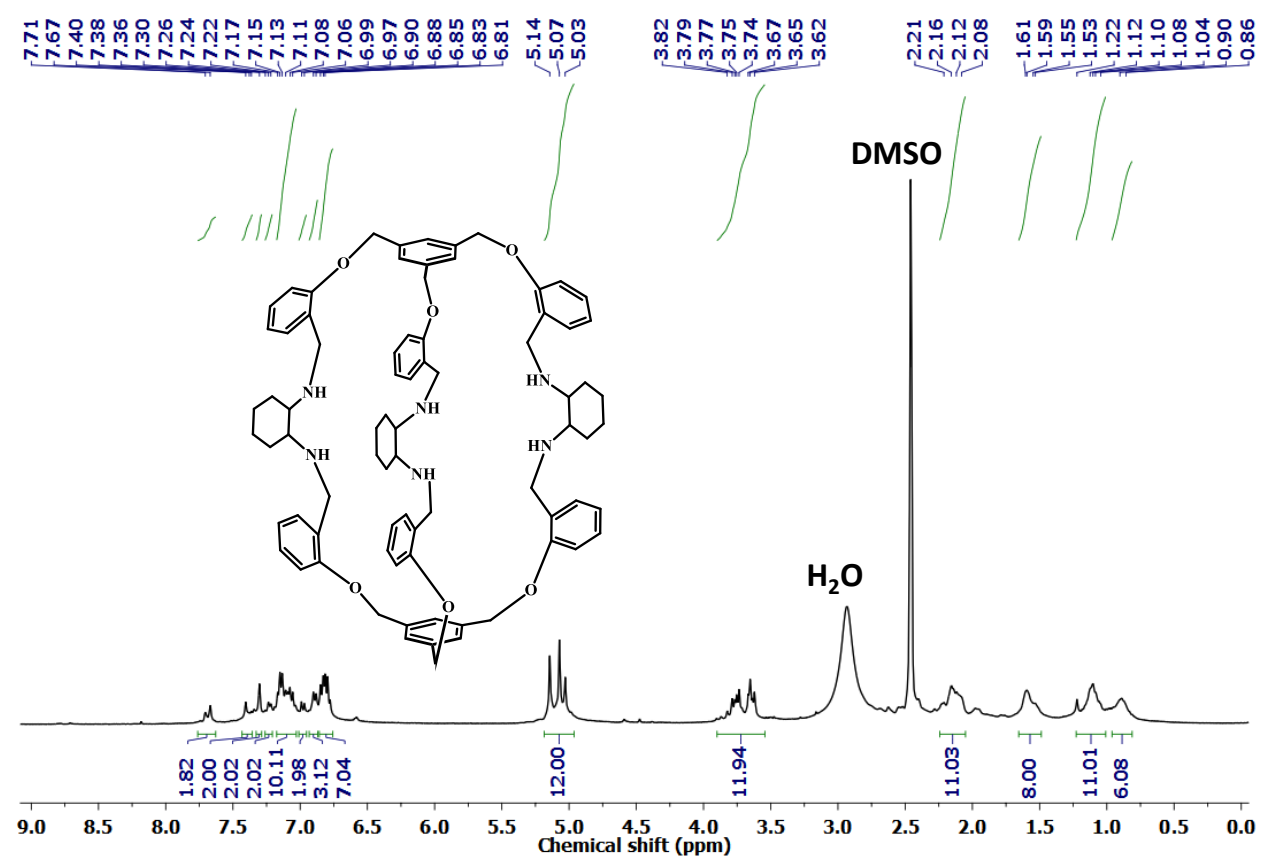

Figure S10. ${ }^{1} \mathrm{H}-\mathrm{NMR}$ of $\boldsymbol{o}$-OC. 


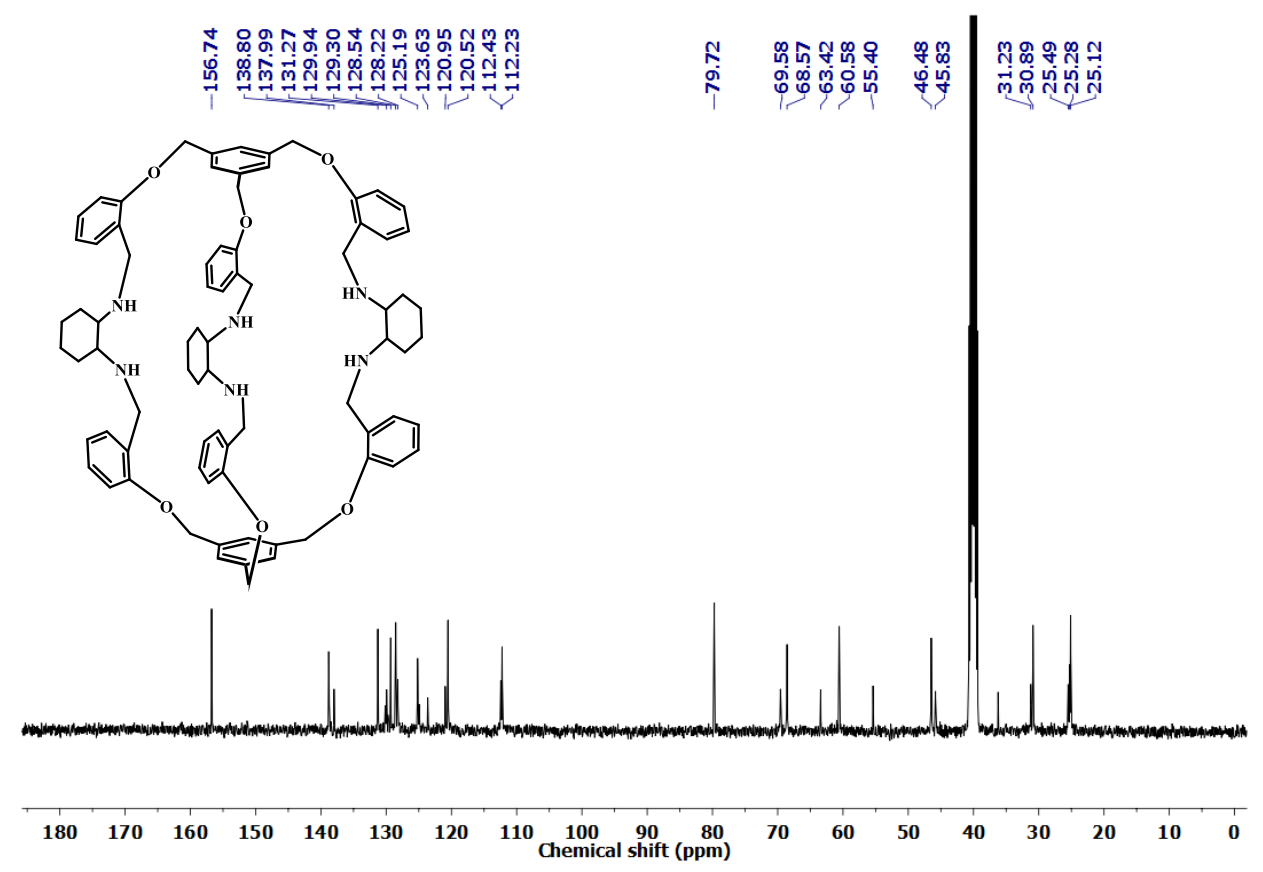

Figure S11. ${ }^{13} \mathrm{C}$-NMR of $\boldsymbol{o}$-OC.

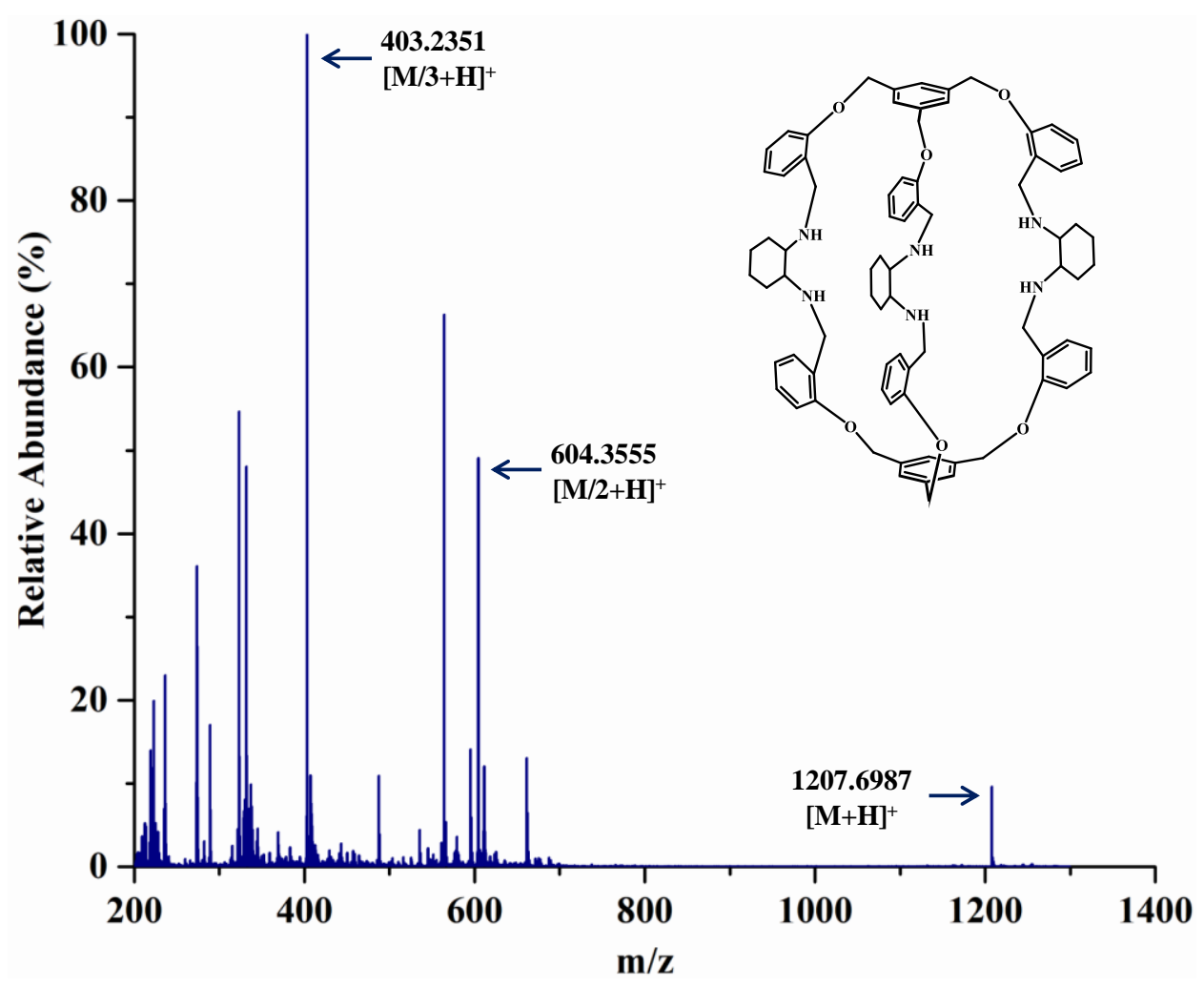

Figure S12. ESI-MS spectrum (positive mode) of $\boldsymbol{o}$-OC. 


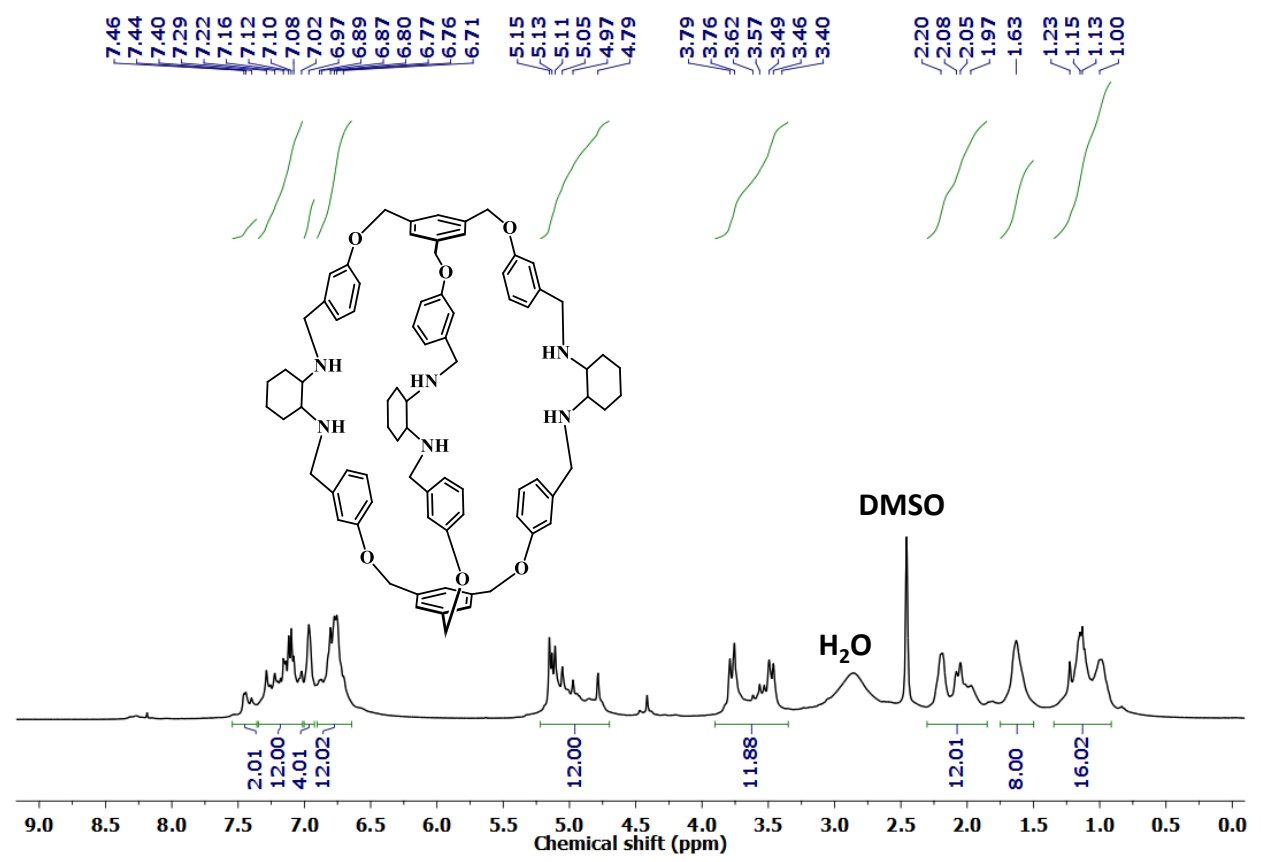

Figure S13. ${ }^{1} \mathrm{H}-\mathrm{NMR}$ of $\boldsymbol{m}$-OC.

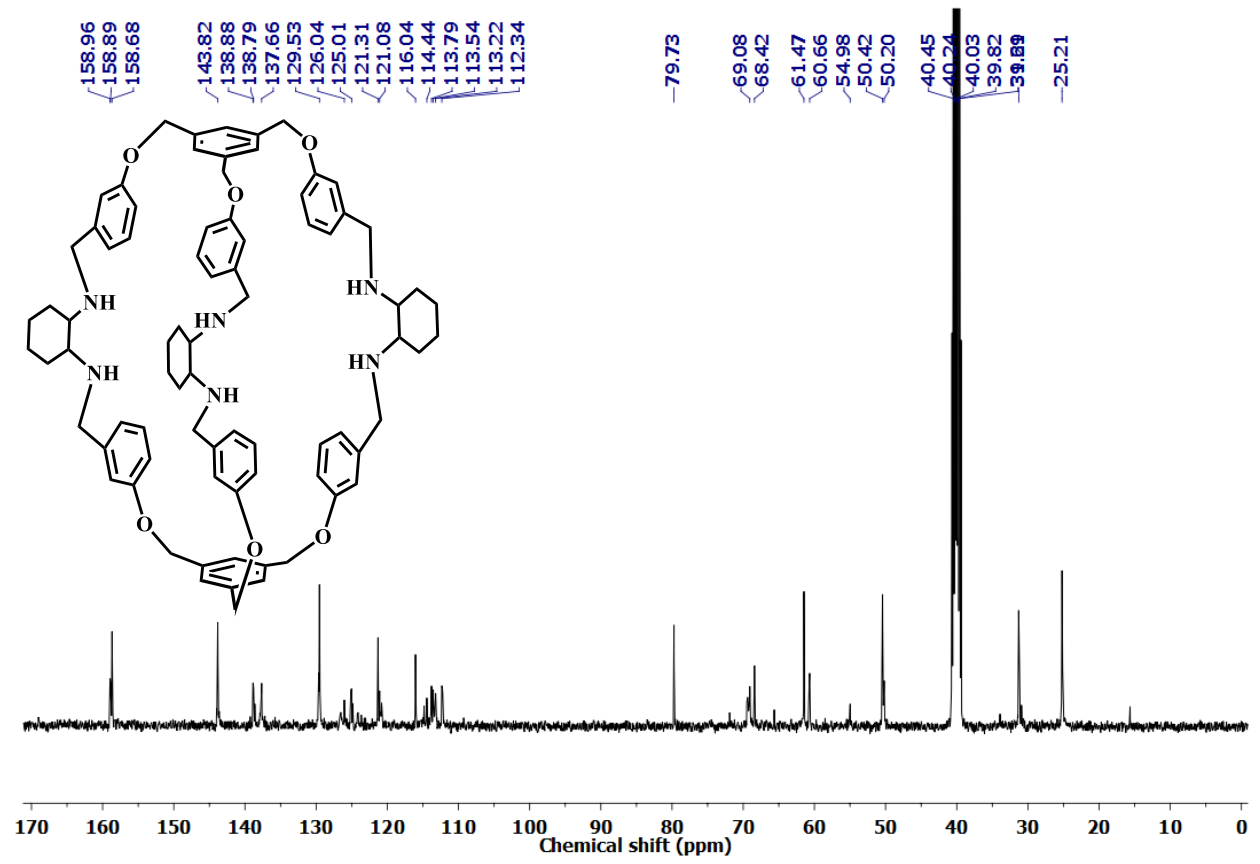

Figure S14. ${ }^{13} \mathrm{C}-\mathrm{NMR}$ of $\boldsymbol{m}$-OC. 


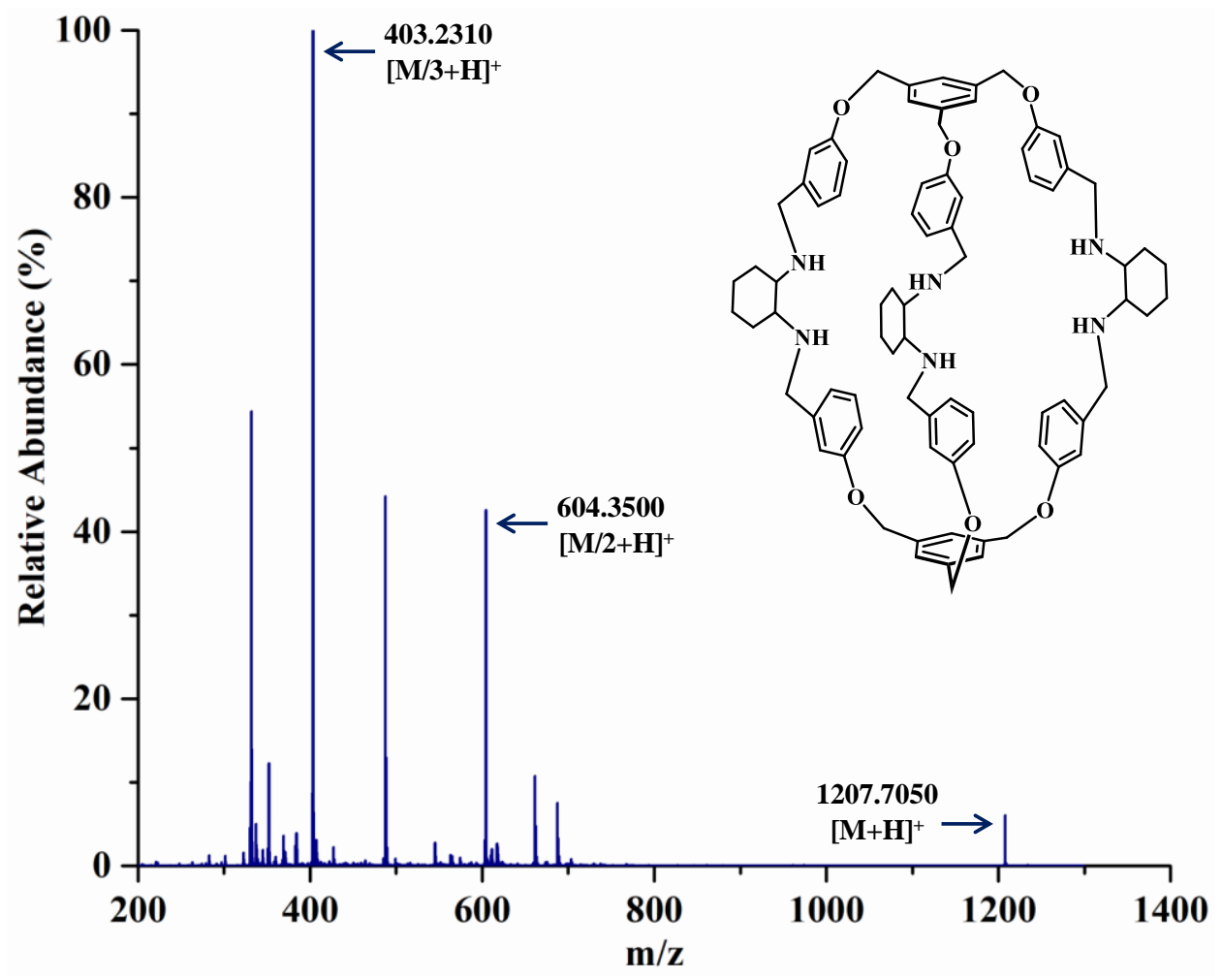

Figure S15. ESI-MS spectrum (positive mode) of $\boldsymbol{m}$-OC.

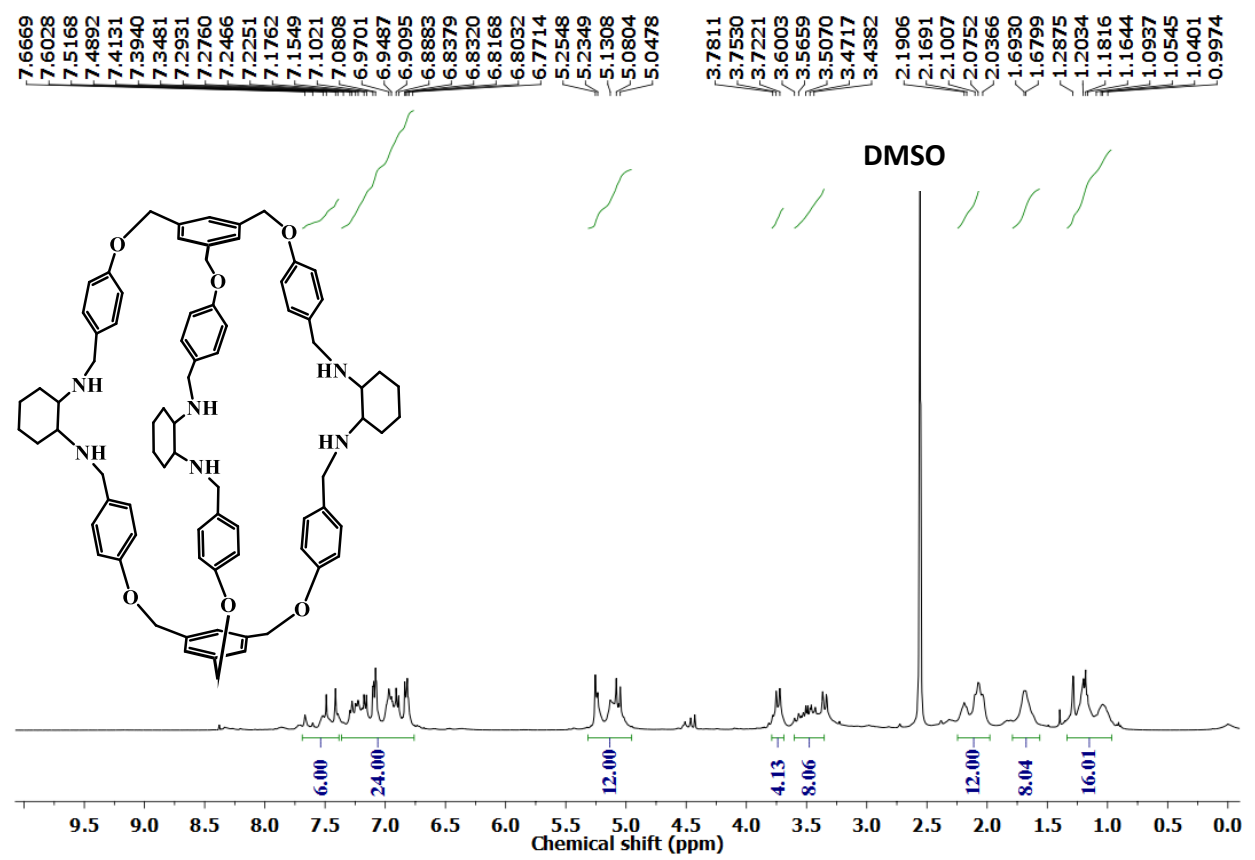

Figure S16. ${ }^{1} \mathrm{H}-\mathrm{NMR}$ of $\boldsymbol{p}$-OC. 


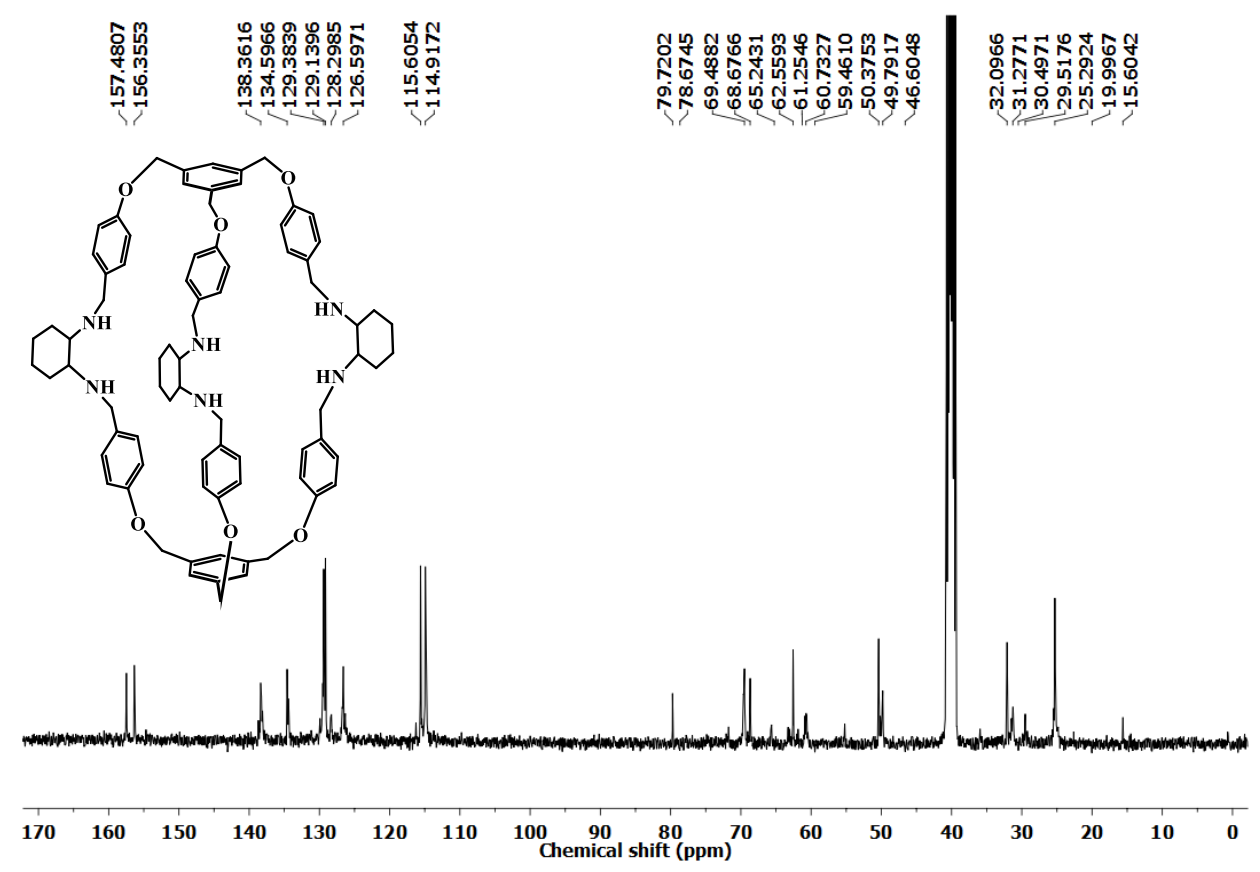

Figure S17. ${ }^{13} \mathrm{C}$-NMR of $\boldsymbol{p}$-OC.

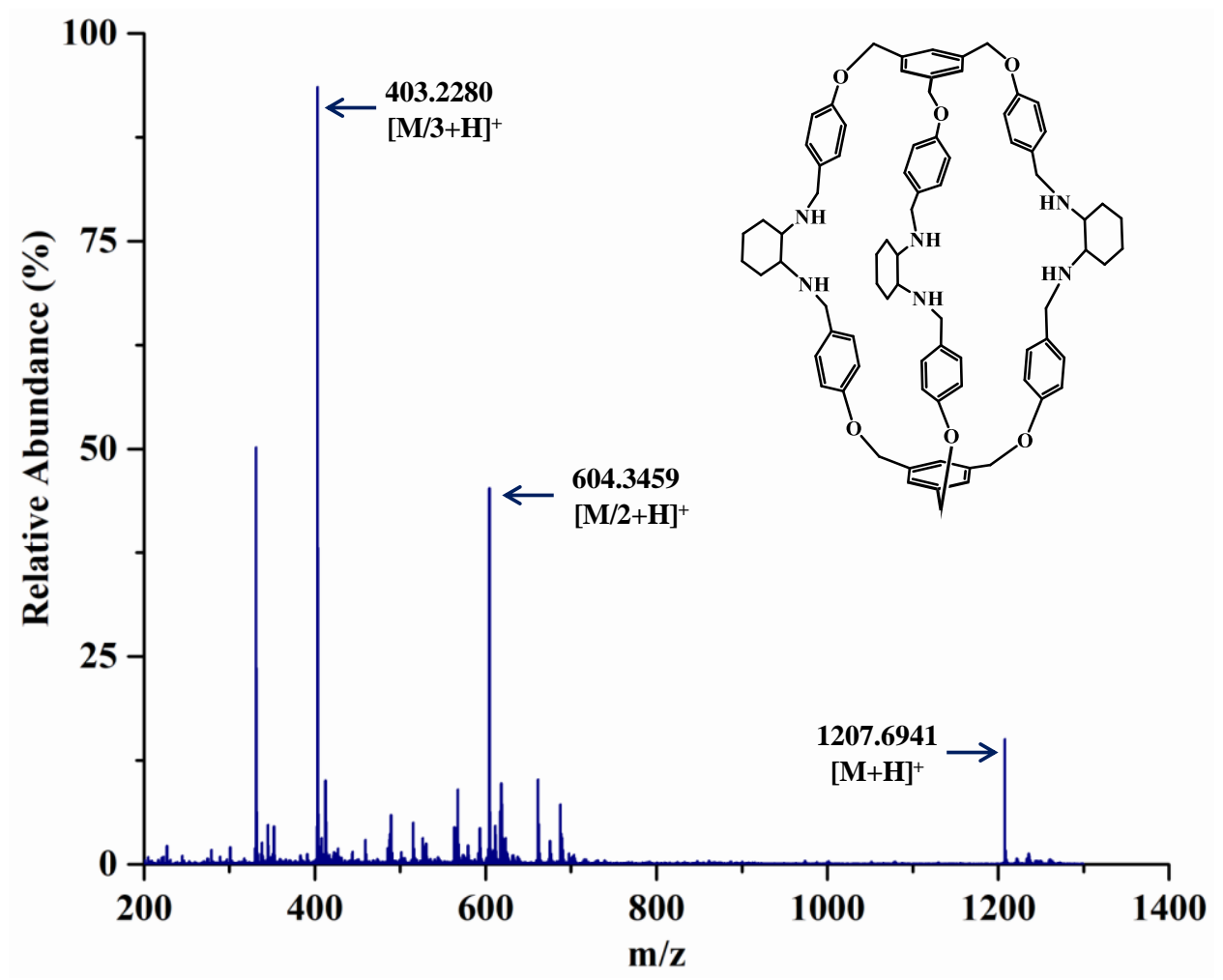

Figure S18. ESI-MS spectrum (positive mode) of $\boldsymbol{p}$-OC. 


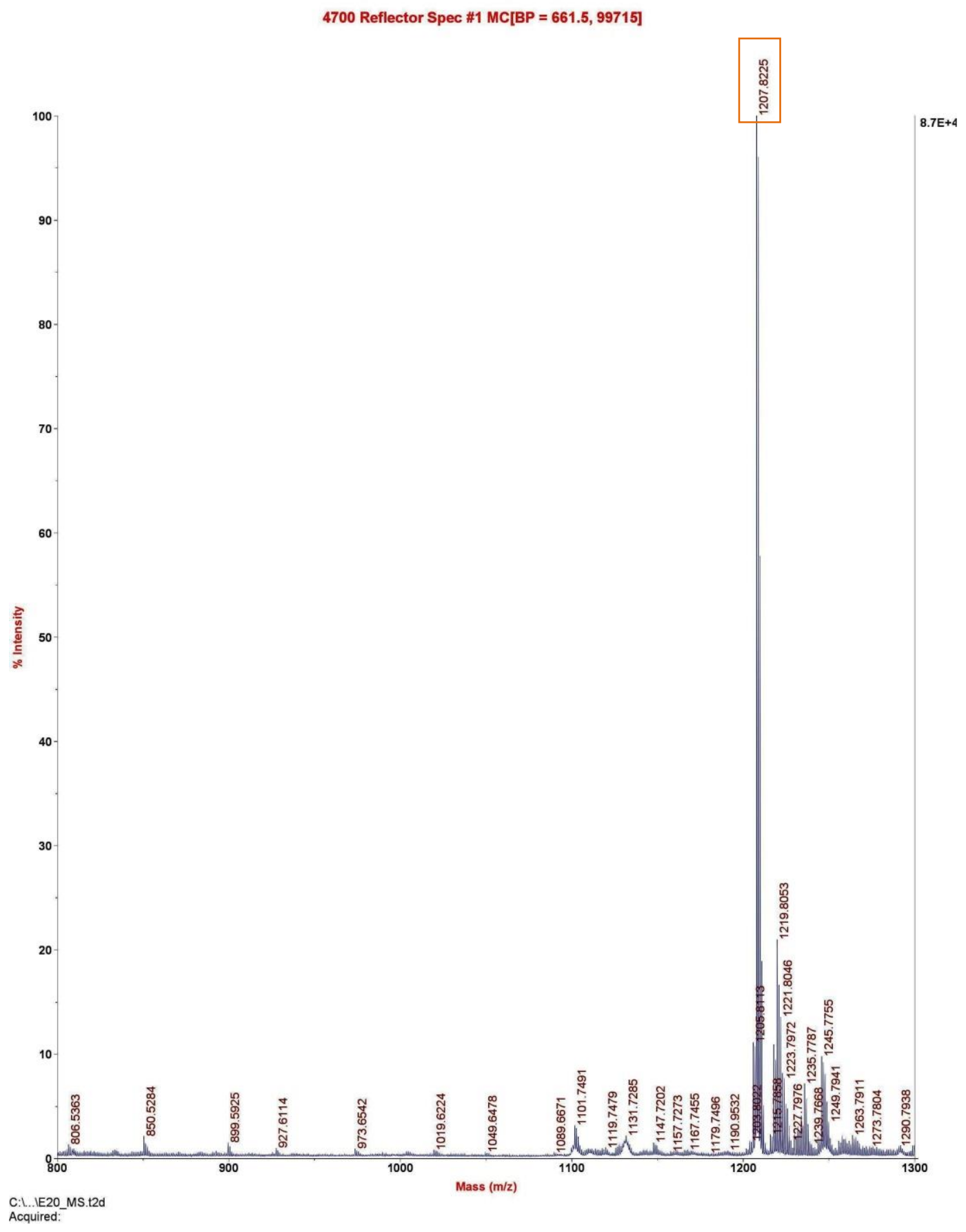

Figure S19. MALDI-TOF spectrum of $\boldsymbol{o}$-OC. 


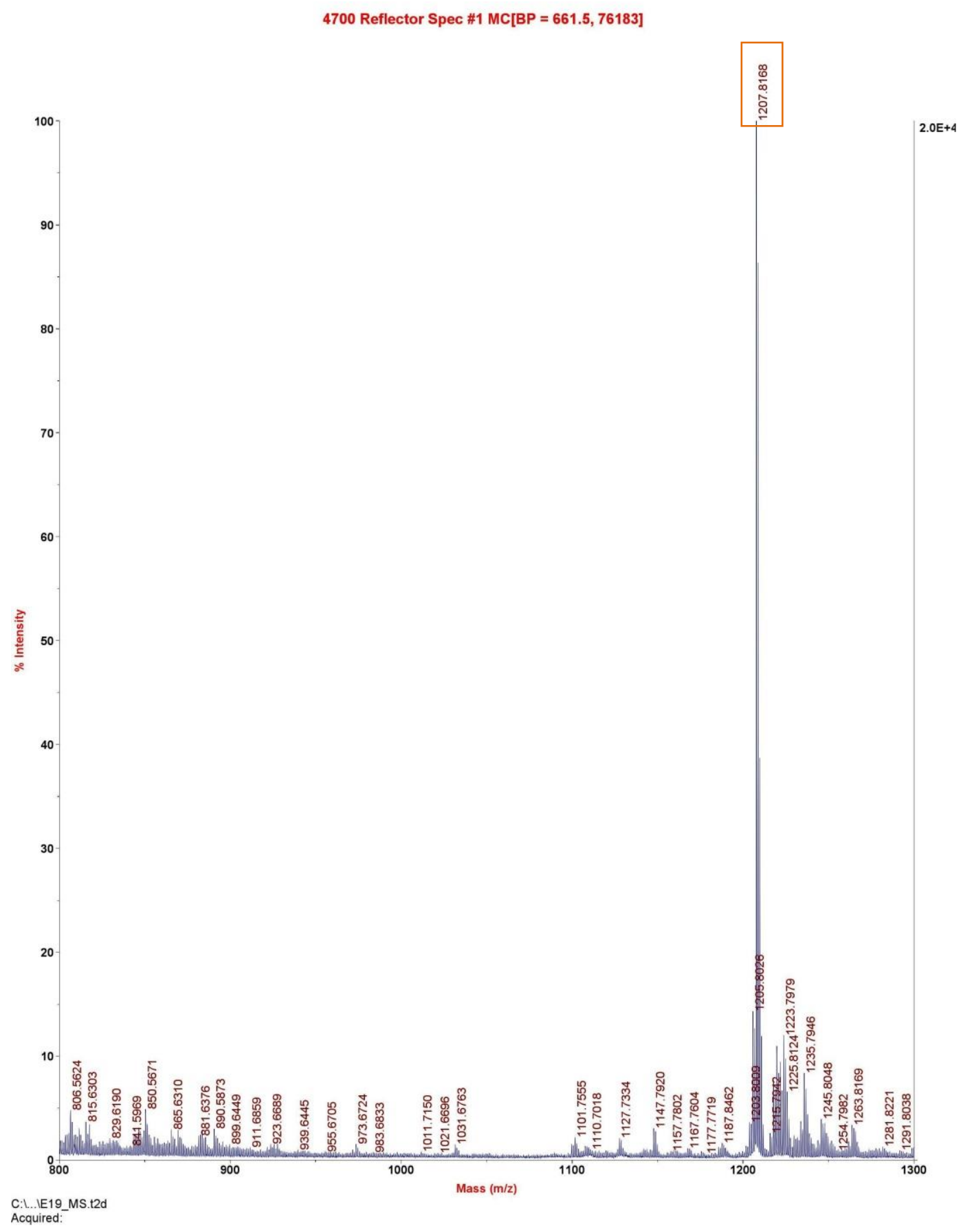

Figure S20. MALDI-TOF spectrum of $\boldsymbol{m}$-OC. 


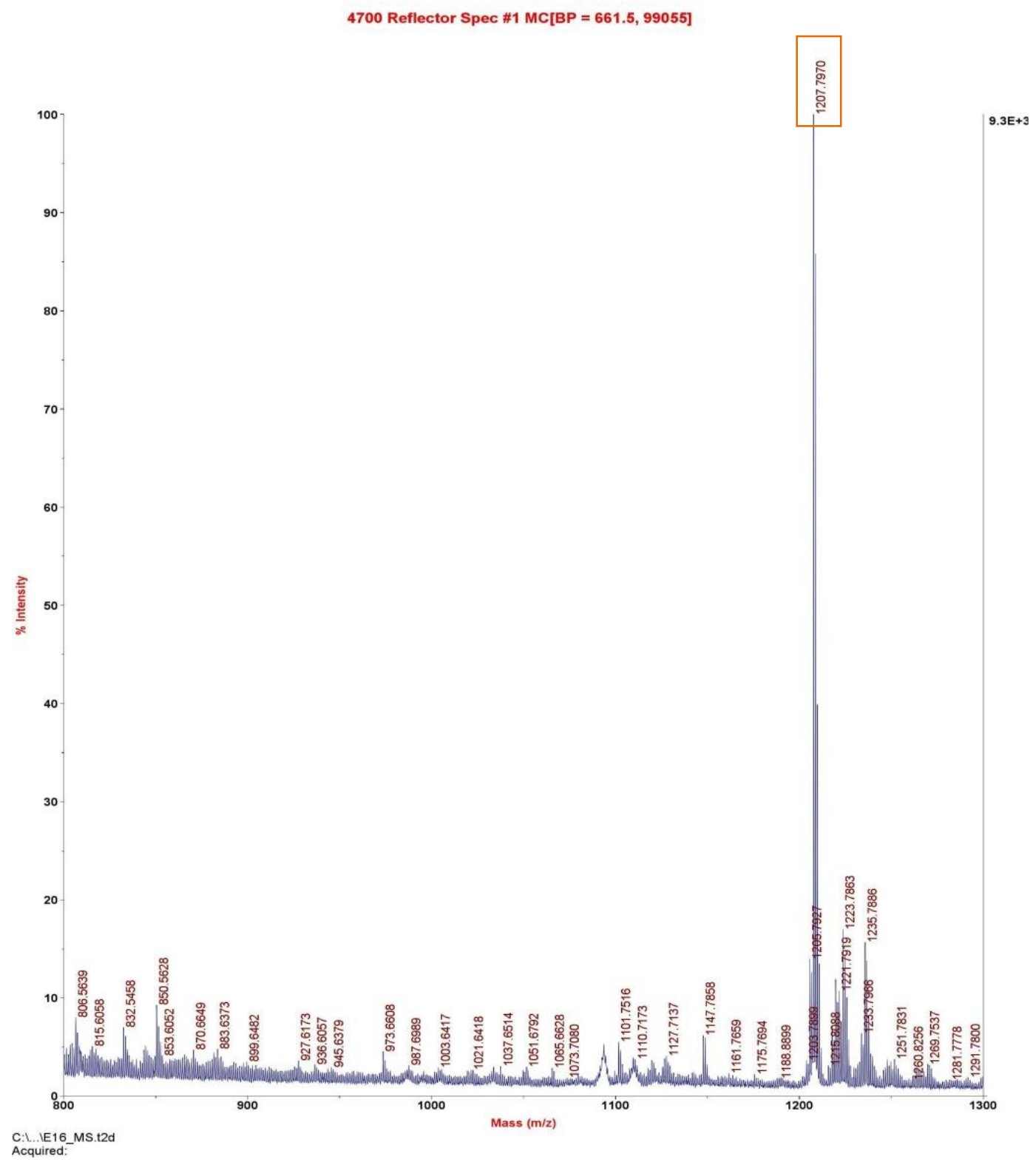

Figure S21. MALDI-TOF spectrum of $\boldsymbol{p}$-OC. 


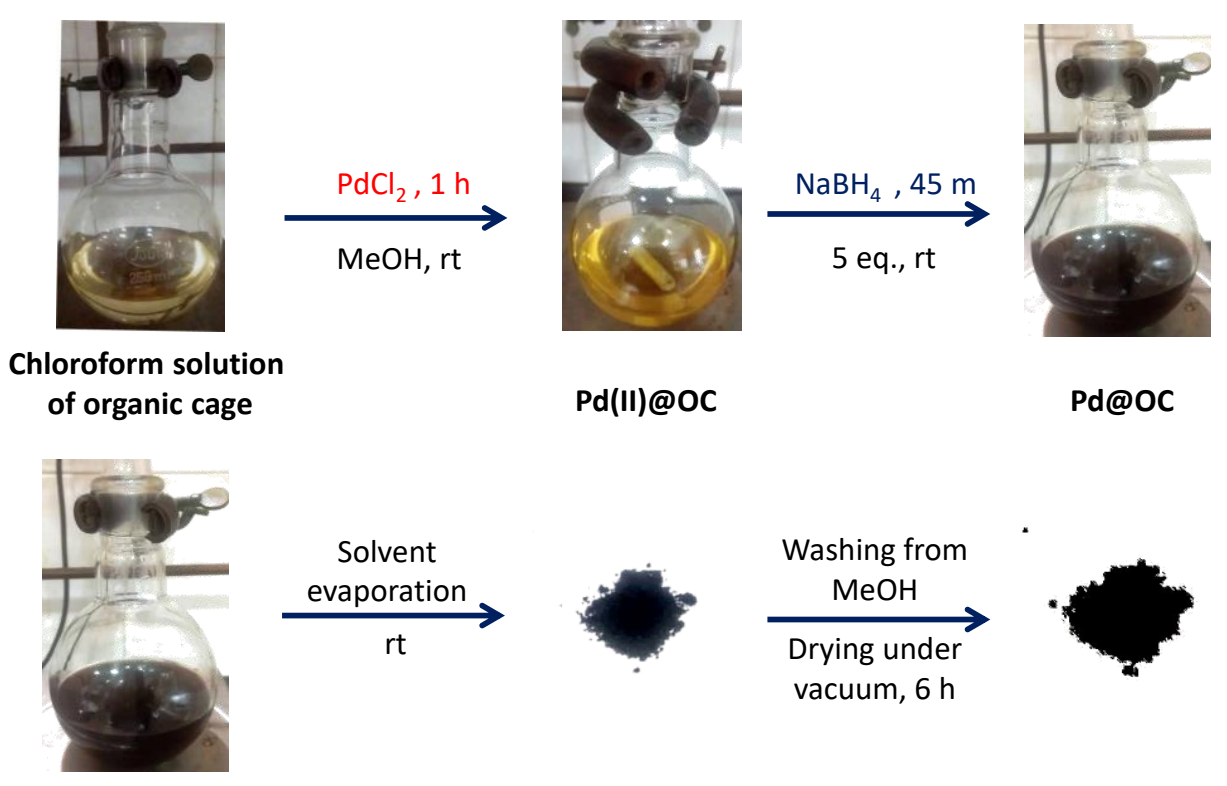

Figure S22. Synthesis of Pd NPs

a.

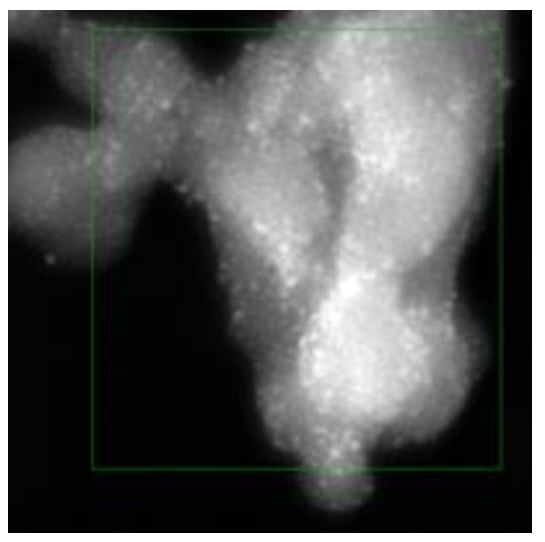

b.

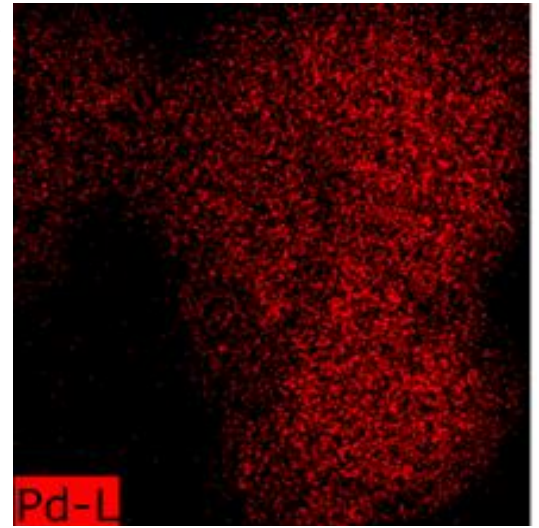

Figure S23. (a) HAADF of $\boldsymbol{o}$-OC and (b) corresponding mapping of Palladium metal. 

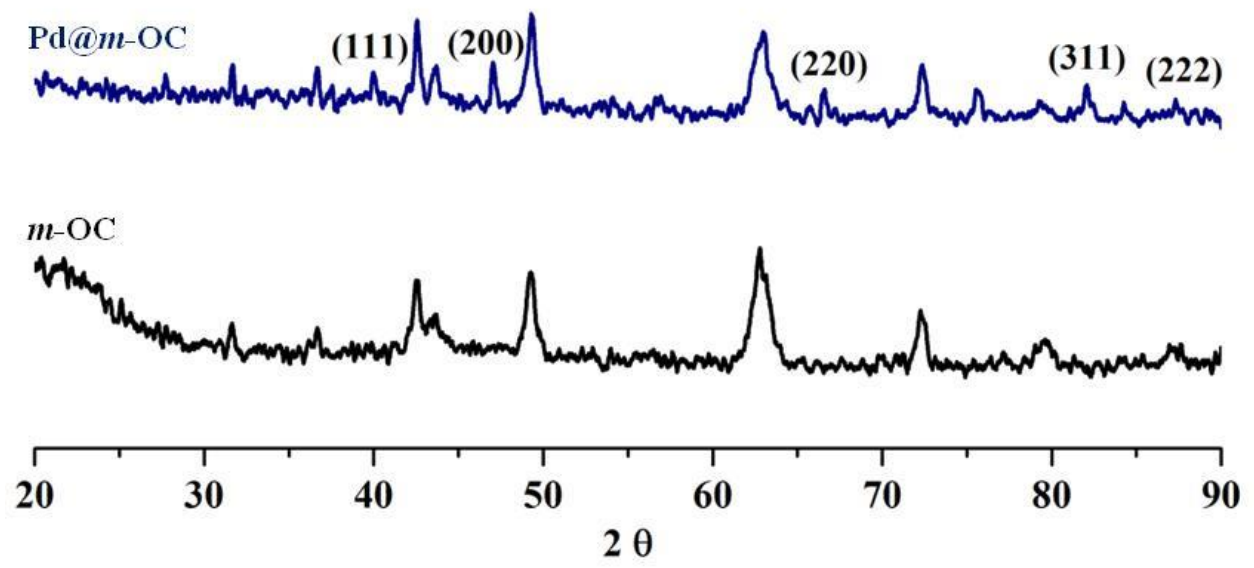

Figure S24. PXRD of $\boldsymbol{m}$-OC (below) and Pd@m-OC (above).
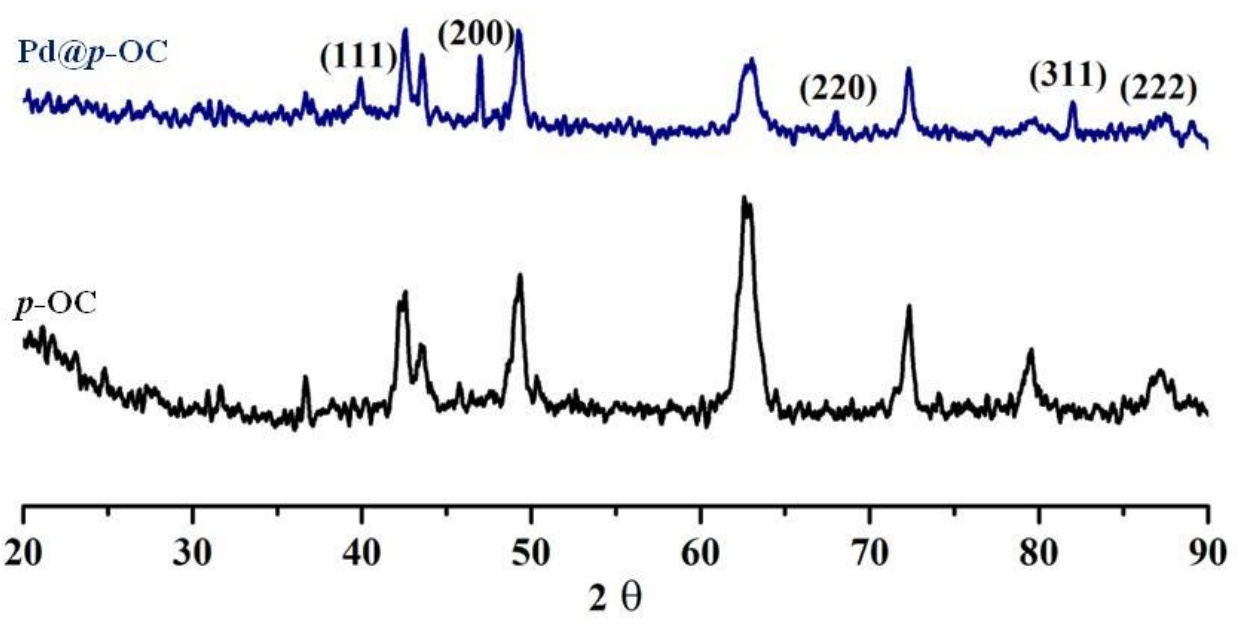

Figure S25. PXRD of $\boldsymbol{p}$-OC (below) and Pd@p-OC (above). 


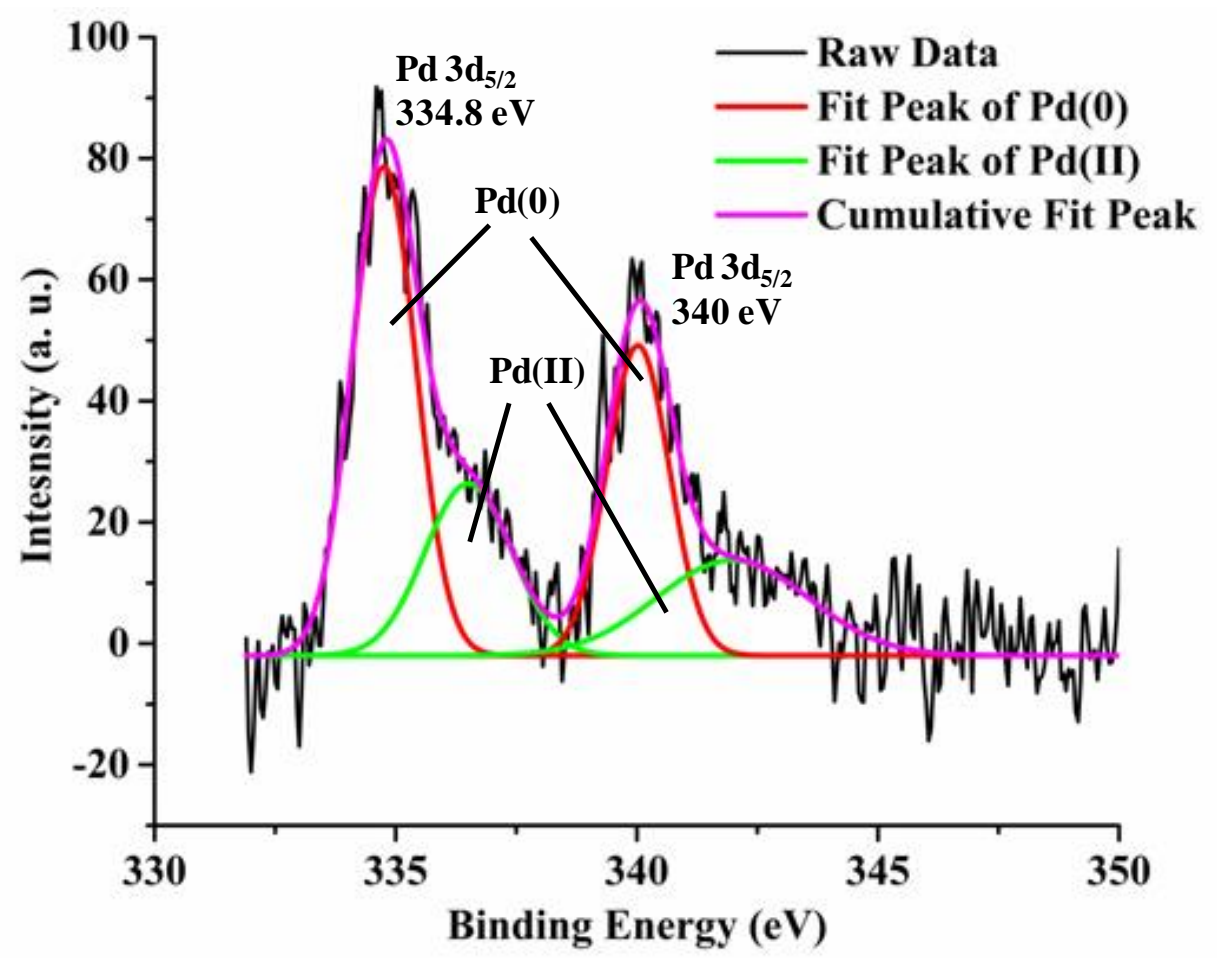

Figure S26. XPS of Pd@m-OC.

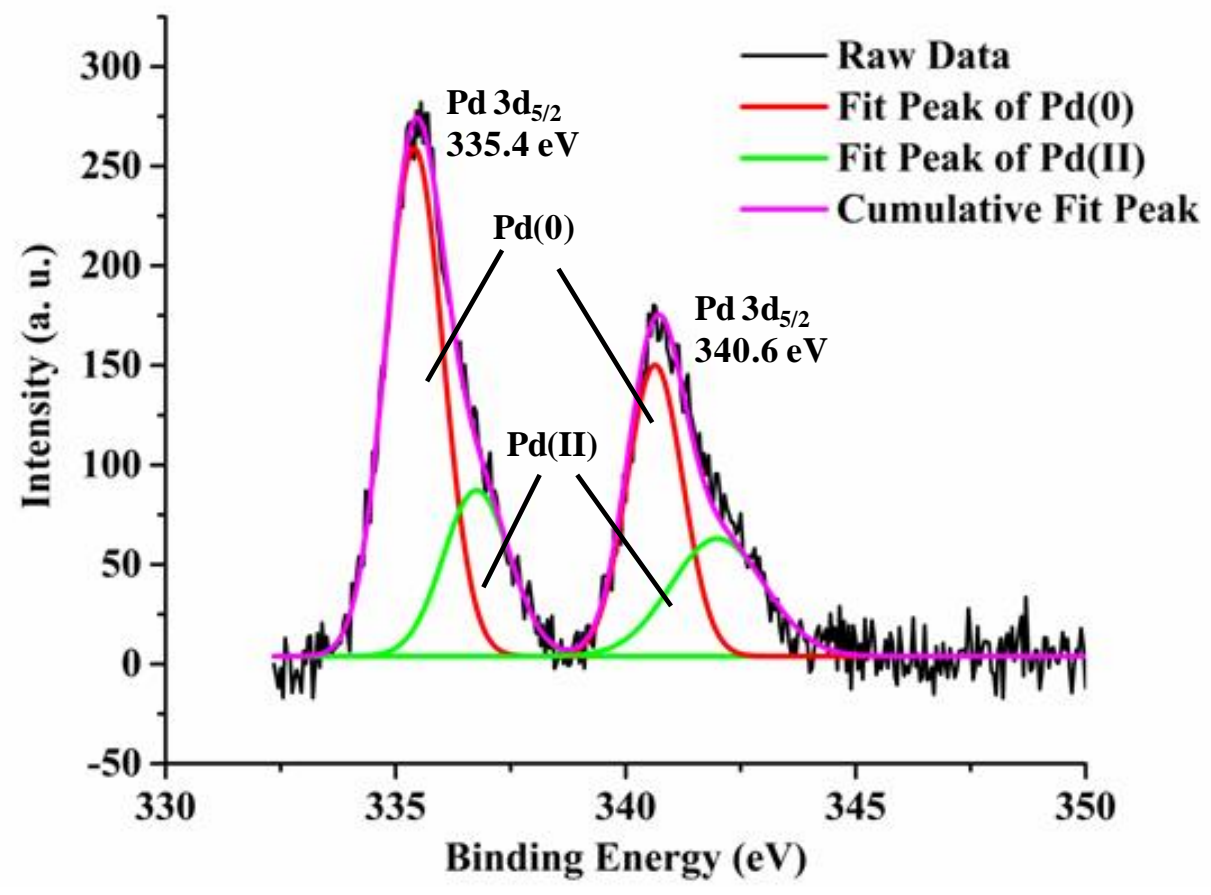

Figure S27. XPS of Pd@p-OC. 


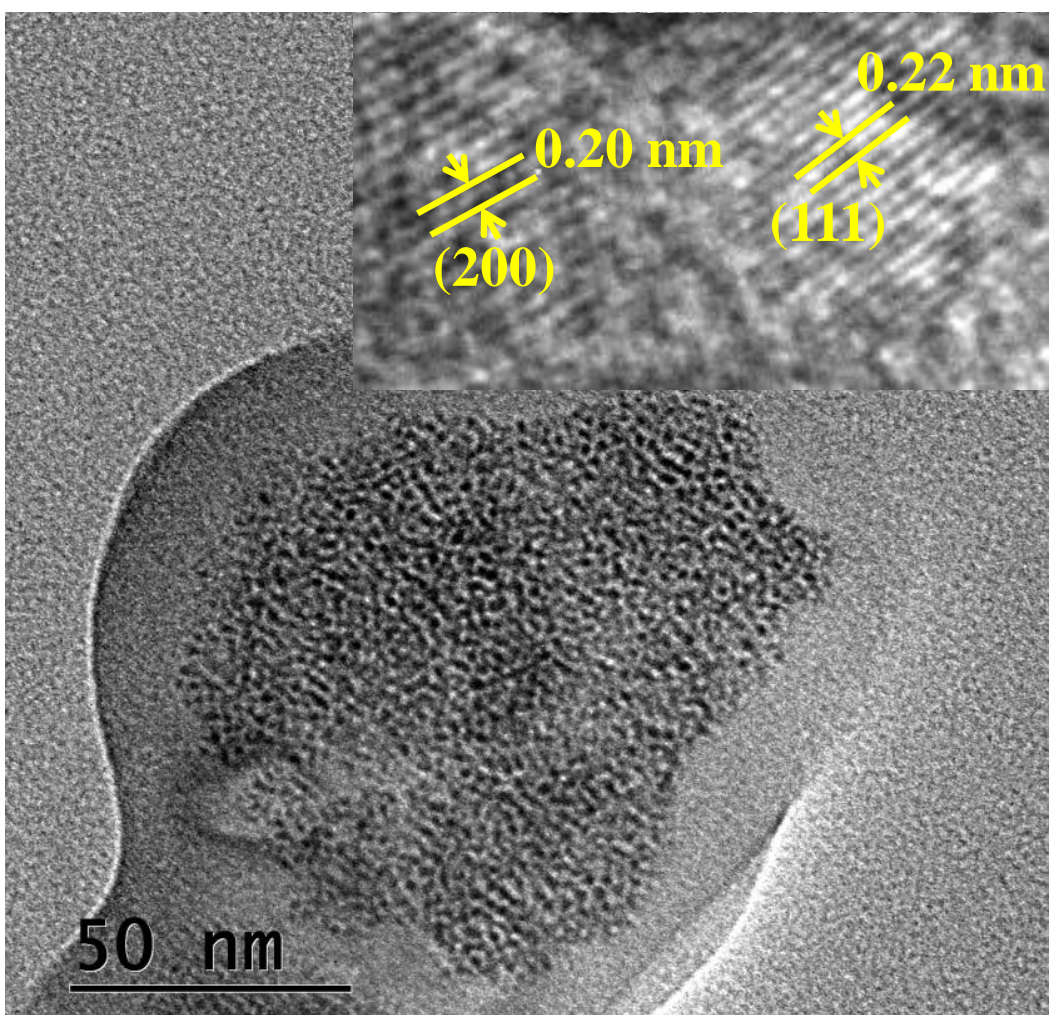

Figure S28. HR-TEM image of Pd@m-OC and lattice fringes (inset image).

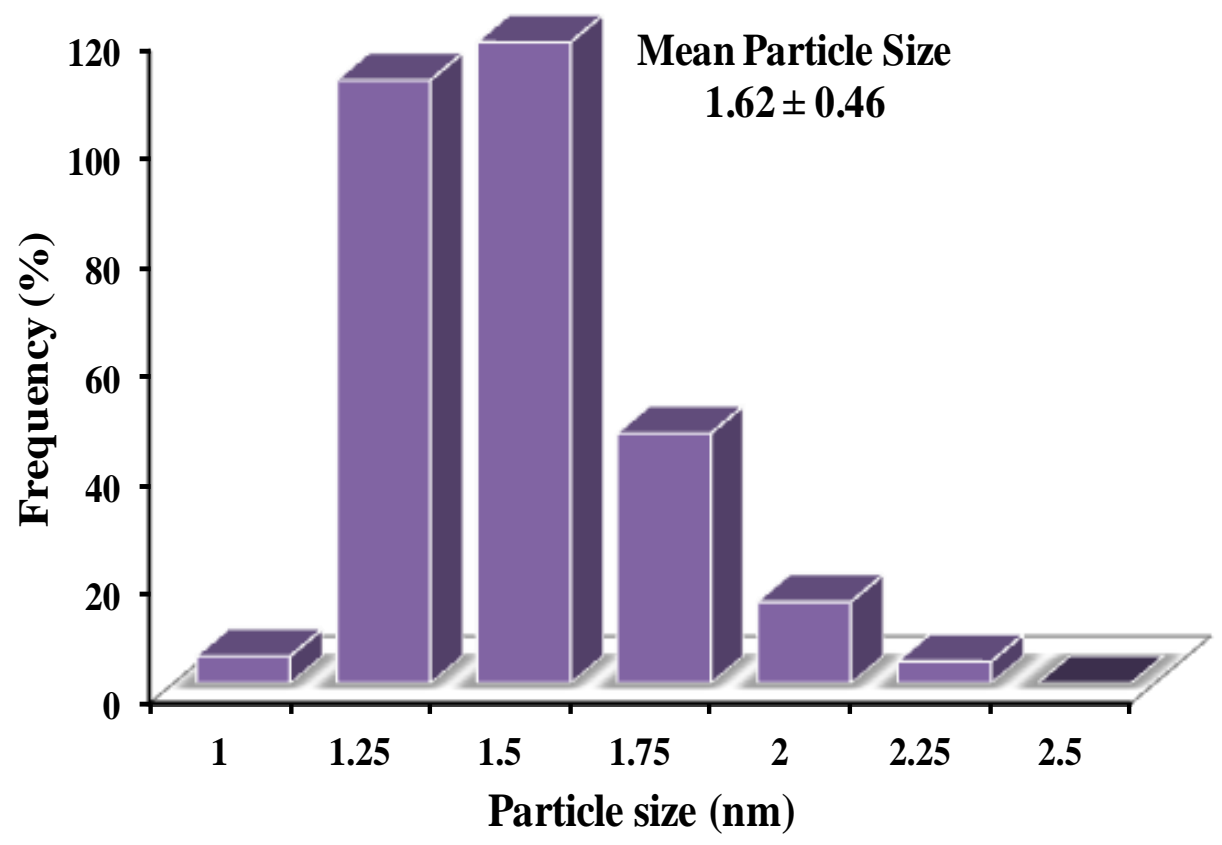

Figure S29. Particle size distribution in Pd@m-OC. 


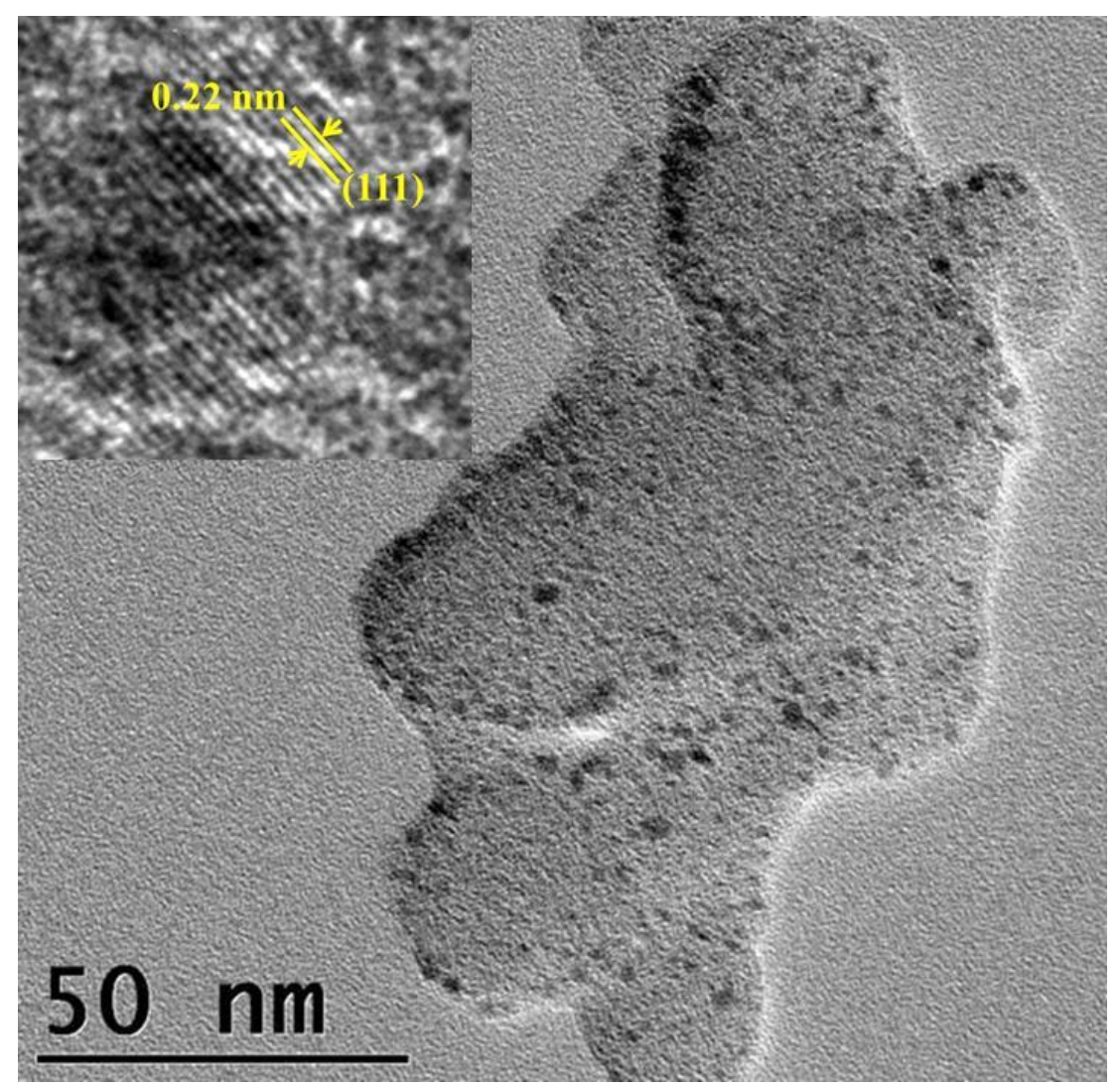

Figure S30. HR-TEM image of Pd@p-OC and lattice fringes (inset image).

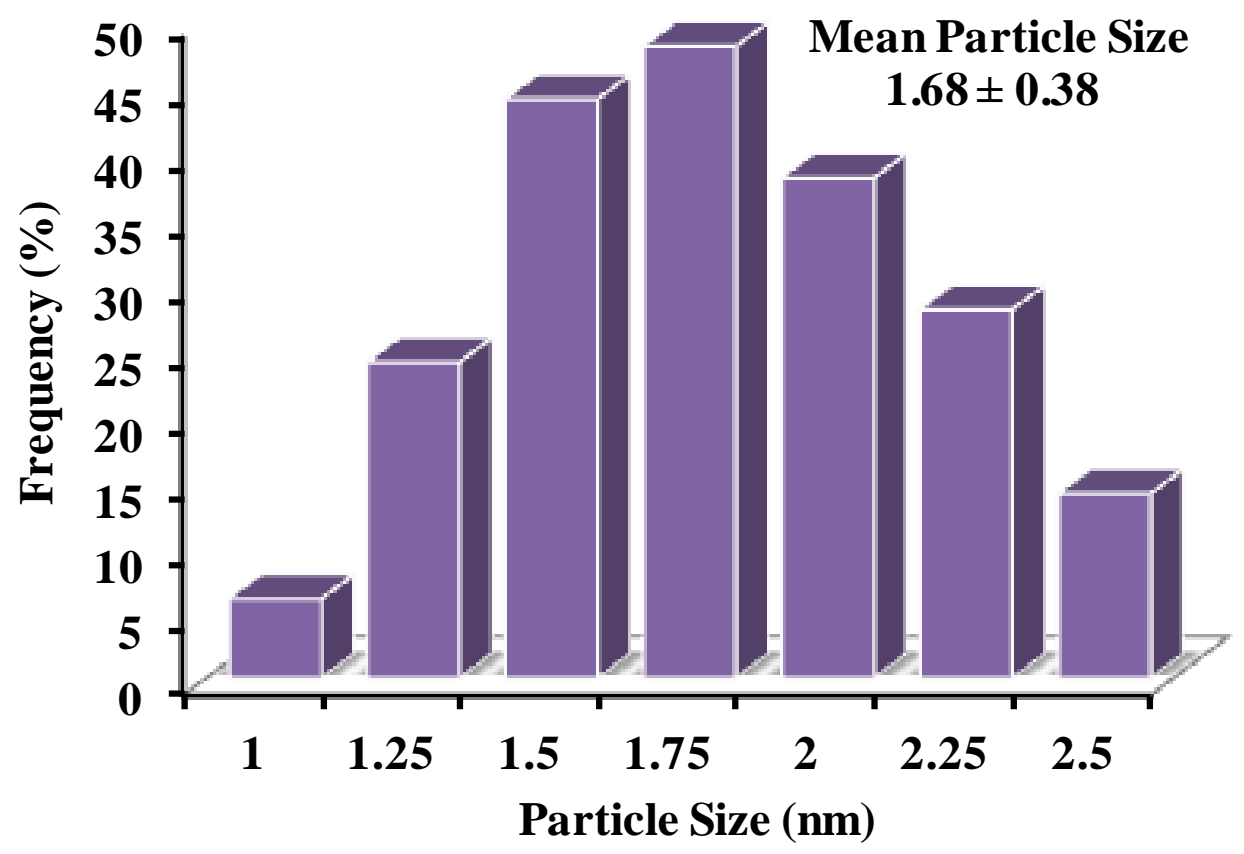

Figure S31. Particle size distribution in Pd@p-OC. 


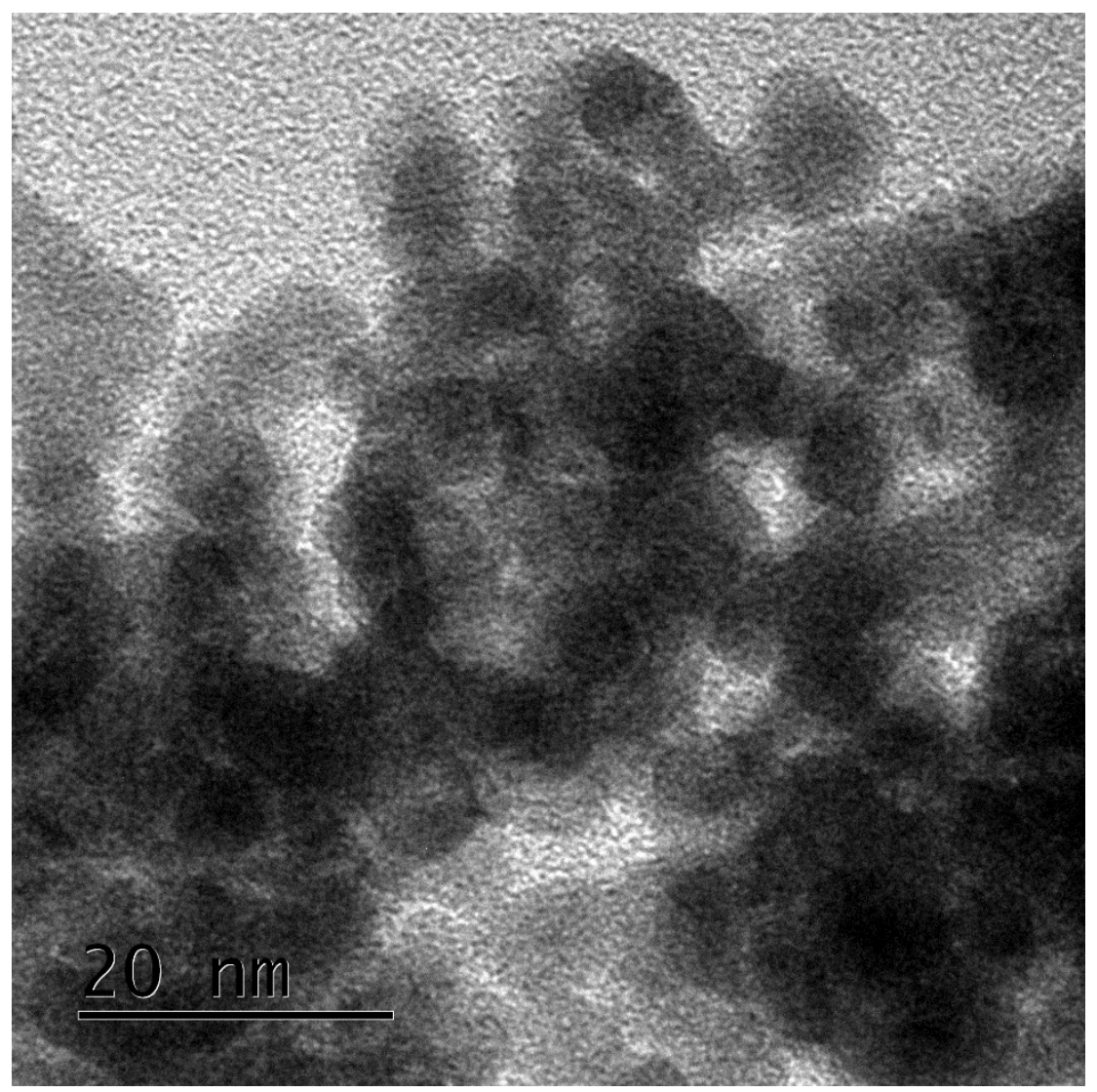

Figure S32. TEM image of Pd NPs stabilized by diaminocyclohexane only.

\section{Conversion Determination}

The allylation of ethyl aceto acetate with allyl methyl carbonate was determined by ${ }^{1} \mathrm{H}$ NMR while in case of dimethyl malonate and acetyl acetone, it was determined through GC Mass. All the products were characterized by ${ }^{1} \mathrm{H}-\mathrm{NMR},{ }^{13} \mathrm{C}$ NMR and ESI-MASS spectroscopy. GC-MS experiment was performed on an Agilent 7890A GC and 5975C MS system. 

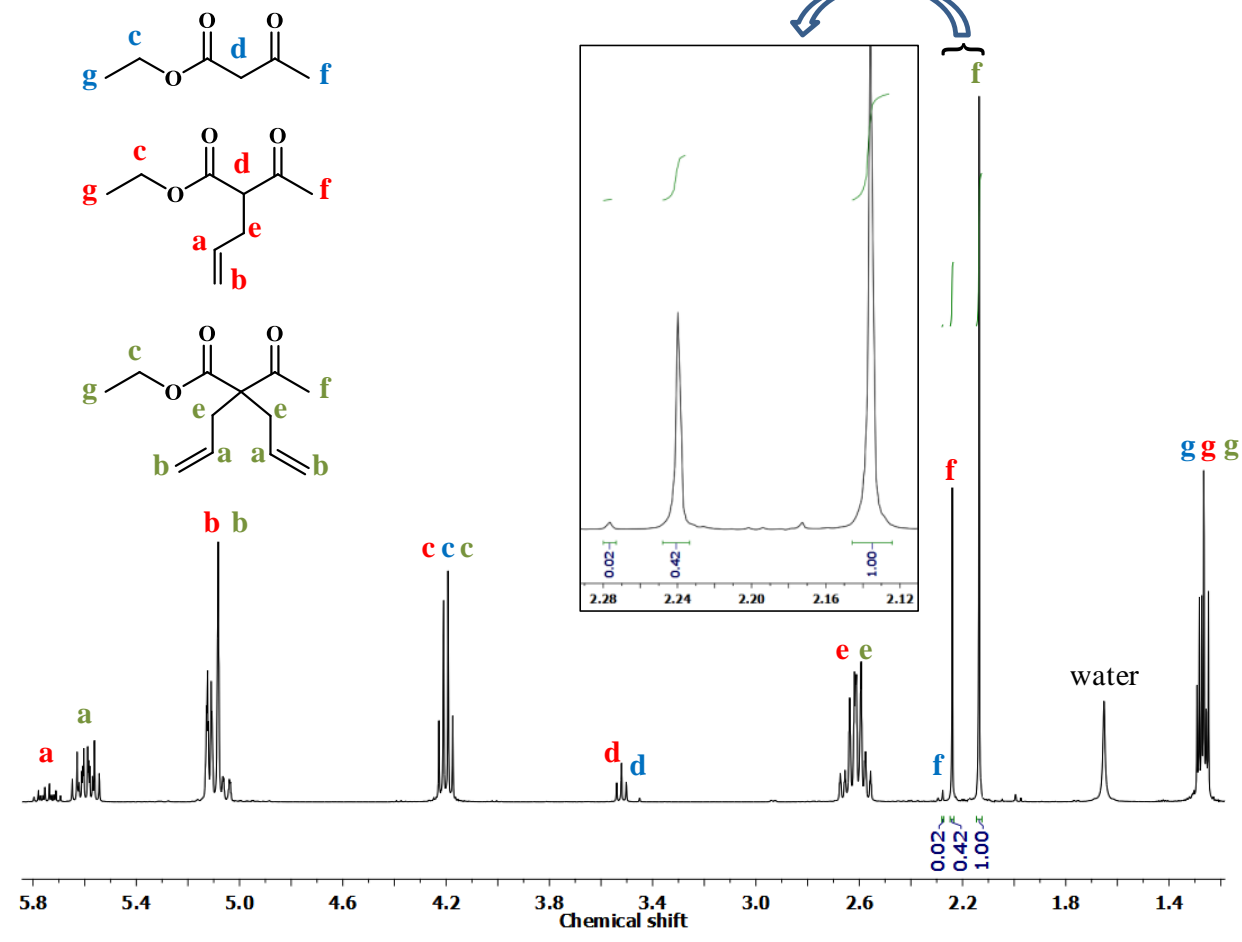

Figure S33. (a) ${ }^{1} \mathrm{H}$ NMR spectrum of a crude mixture of ethyl aceto acetate, mono-allylated product and diallylated product taken at 20 minute (Pd@o-OC); (b) Zoom on the methyl group between $2.10 \mathrm{ppm}$ and $2.30 \mathrm{ppm}$ for conversion determination (here: $1.4 \%$ ethyl aceto acetate, $29 \%$ mono-allylated product, $69 \%$ di-allylated product). 
NMR and Mass of Catalytic Products
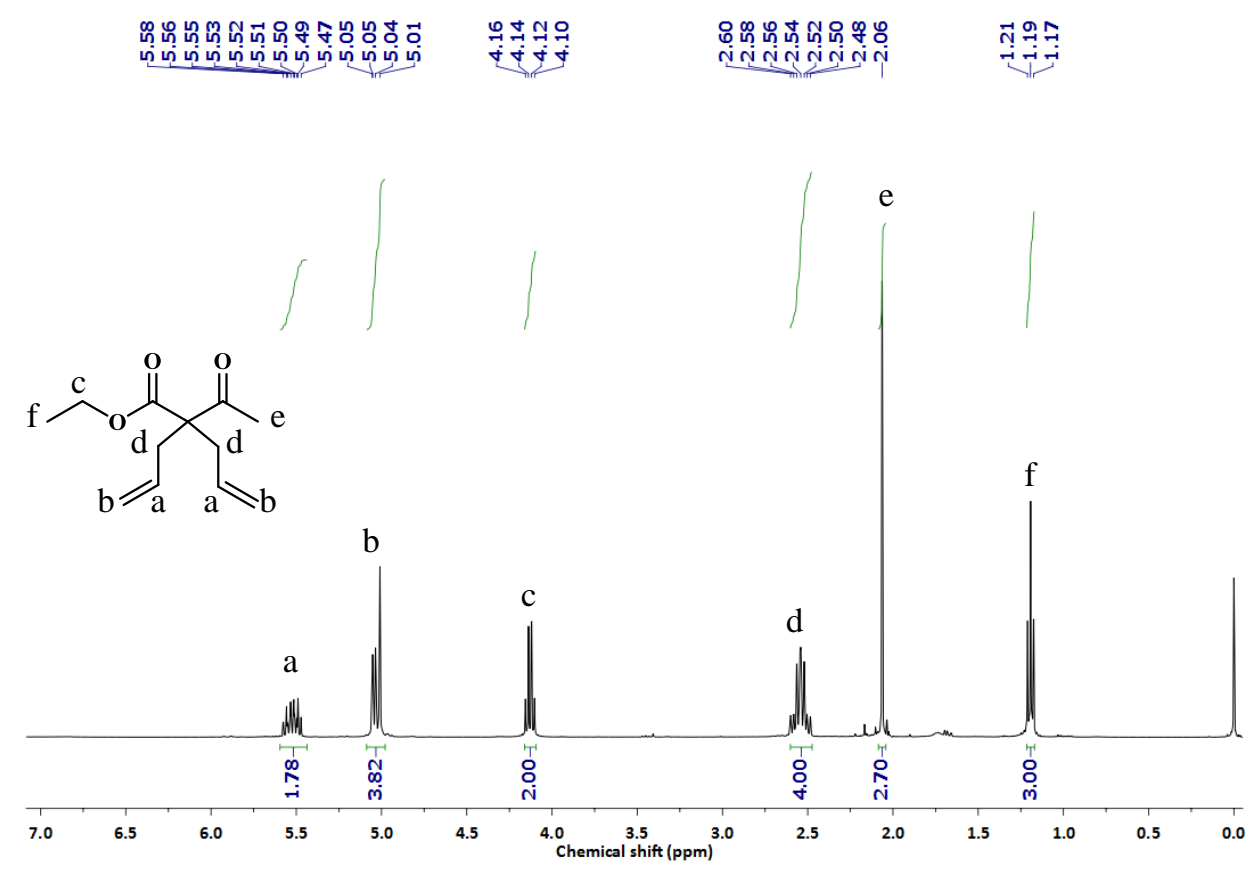

Figure S34. ${ }^{1} \mathrm{H}$ NMR spectrum of ethyl 2-acetyl-2-allylpent-4-enoate (4a).

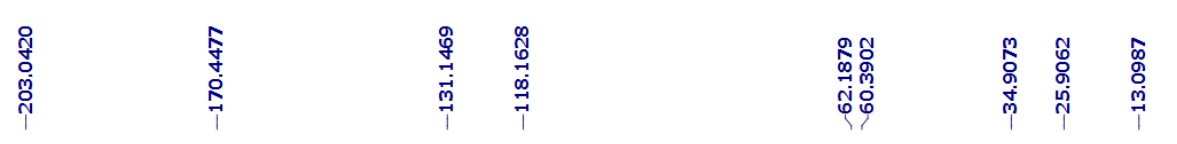<smiles>C=CC(C=C)(C(C)=O)C(=O)CCC</smiles>

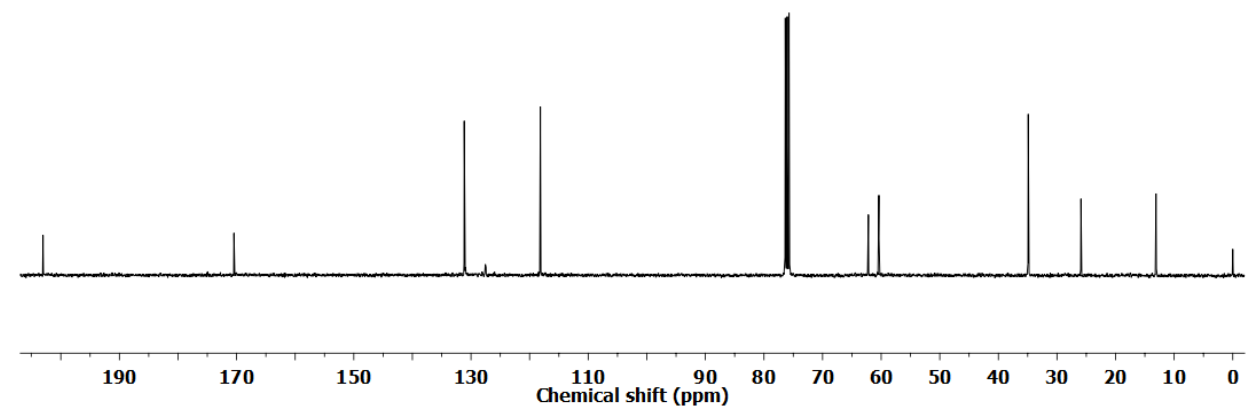

Figure S35. ${ }^{13} \mathrm{C}$ NMR spectrum of ethyl 2-acetyl-2-allylpent-4-enoate (4a). 


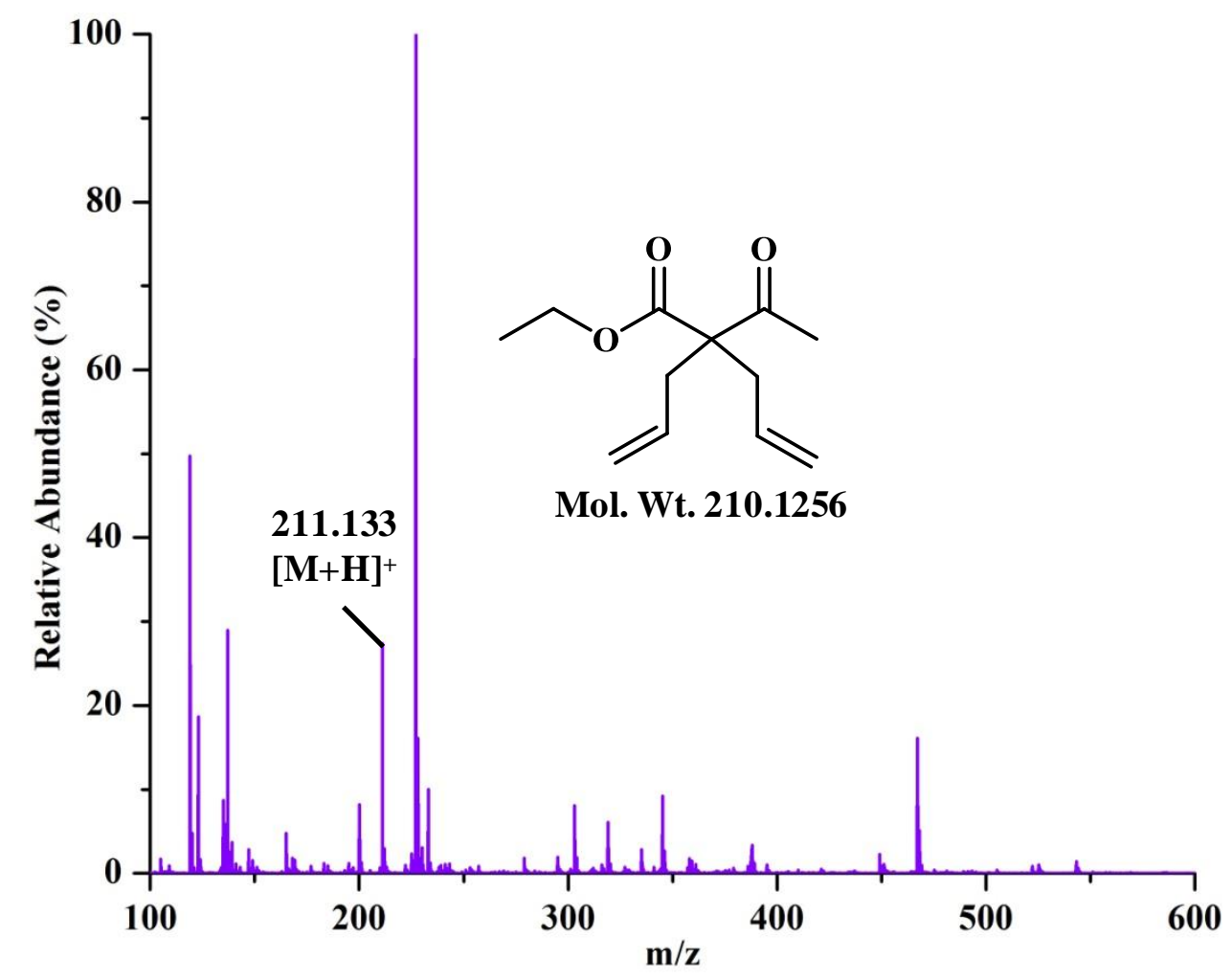

Figure S36. ESI-MS (positive mode) of ethyl 2-acetyl-2-allylpent-4-enoate (4a).

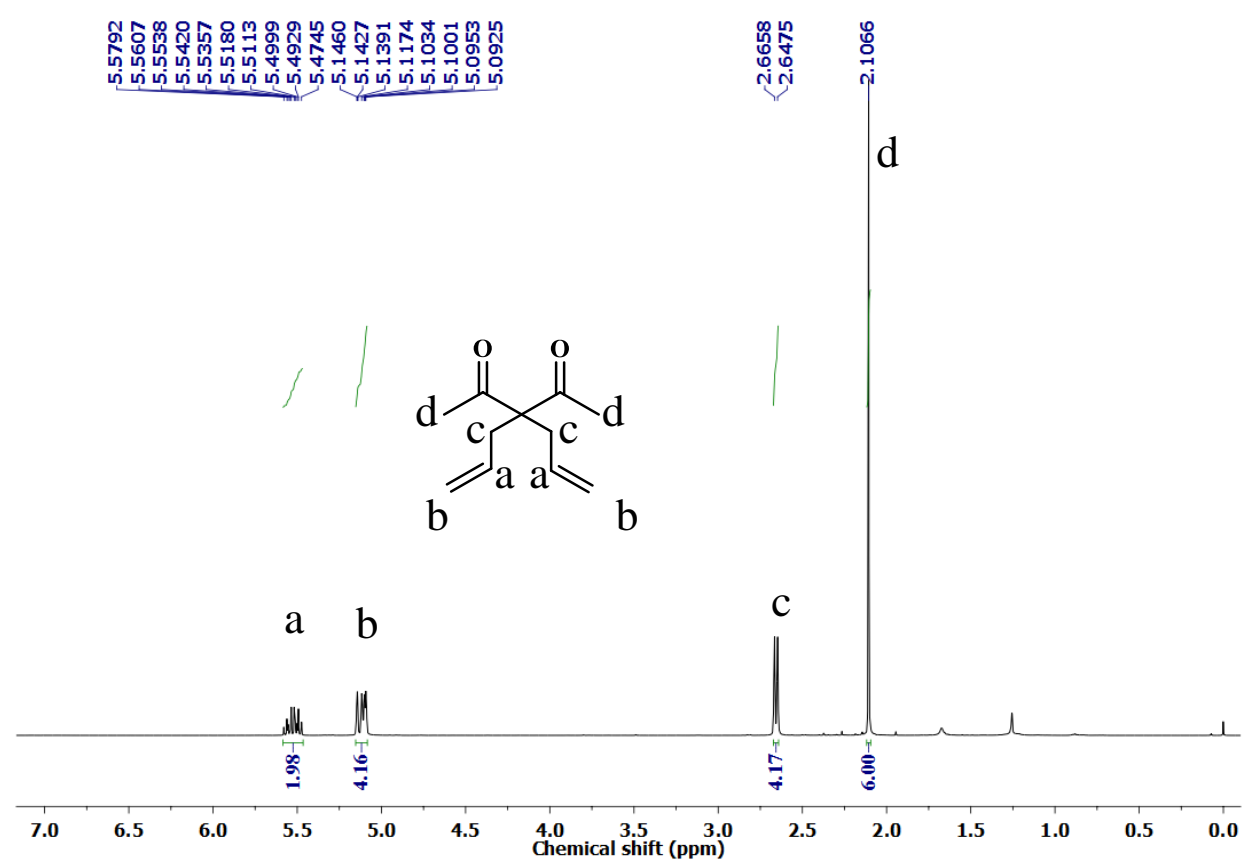

Figure S37. ${ }^{1} \mathrm{H}$ NMR spectrum of 3,3-Diallylpentane-2,4-dione (4b). 

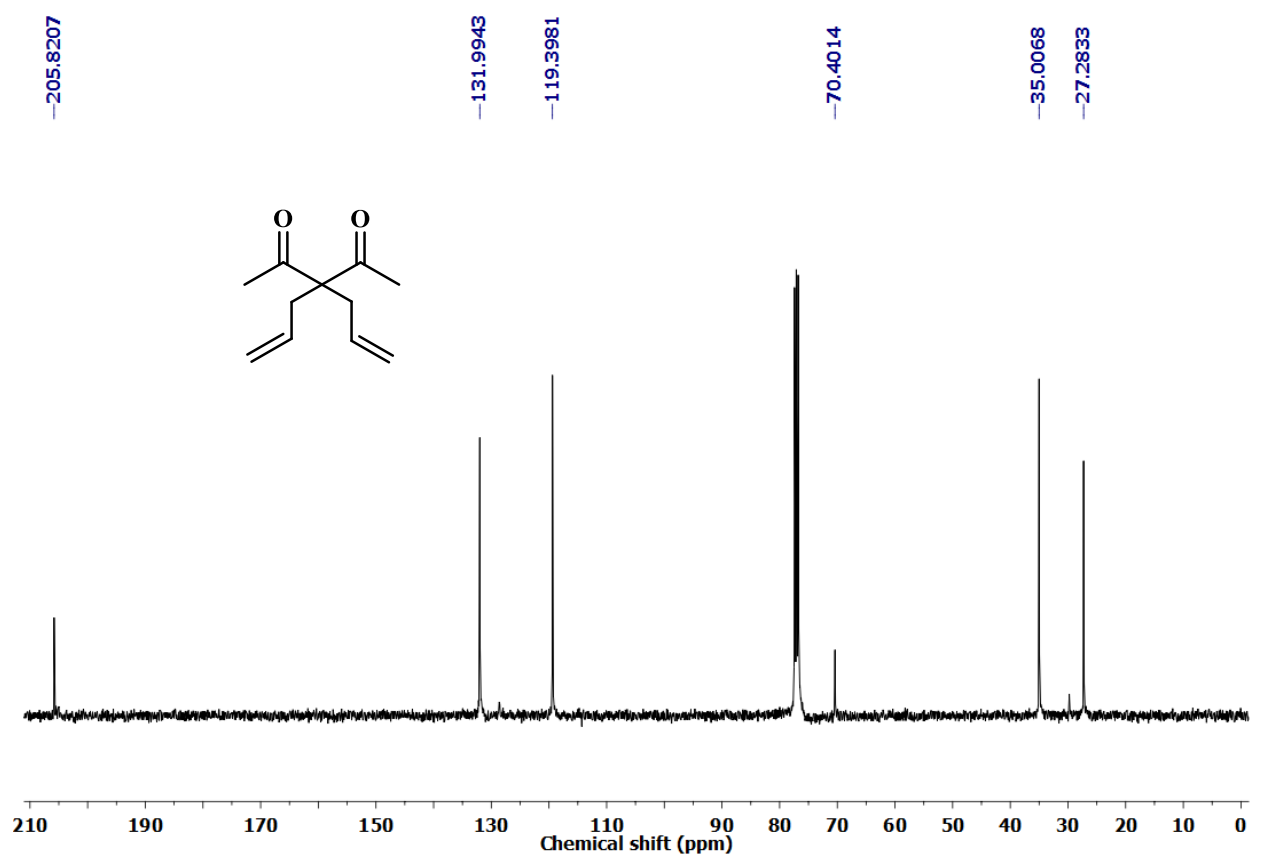

Figure S38. ${ }^{13} \mathrm{C}$ NMR spectrum of 3,3-Diallylpentane-2,4-dione (4b).

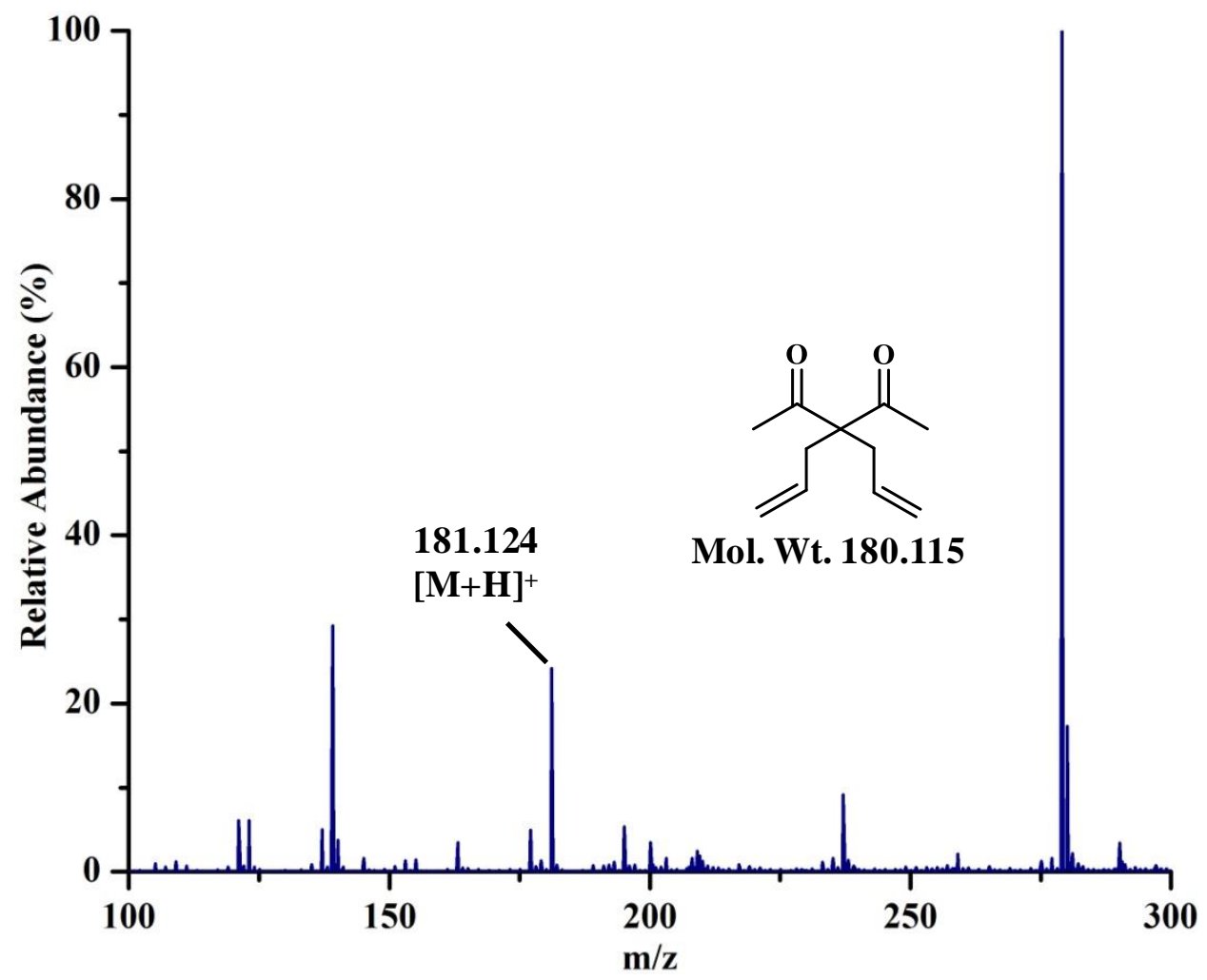

Figure S39. ESI-MS (positive mode) of 3,3-Diallylpentane-2,4-dione (4b). 


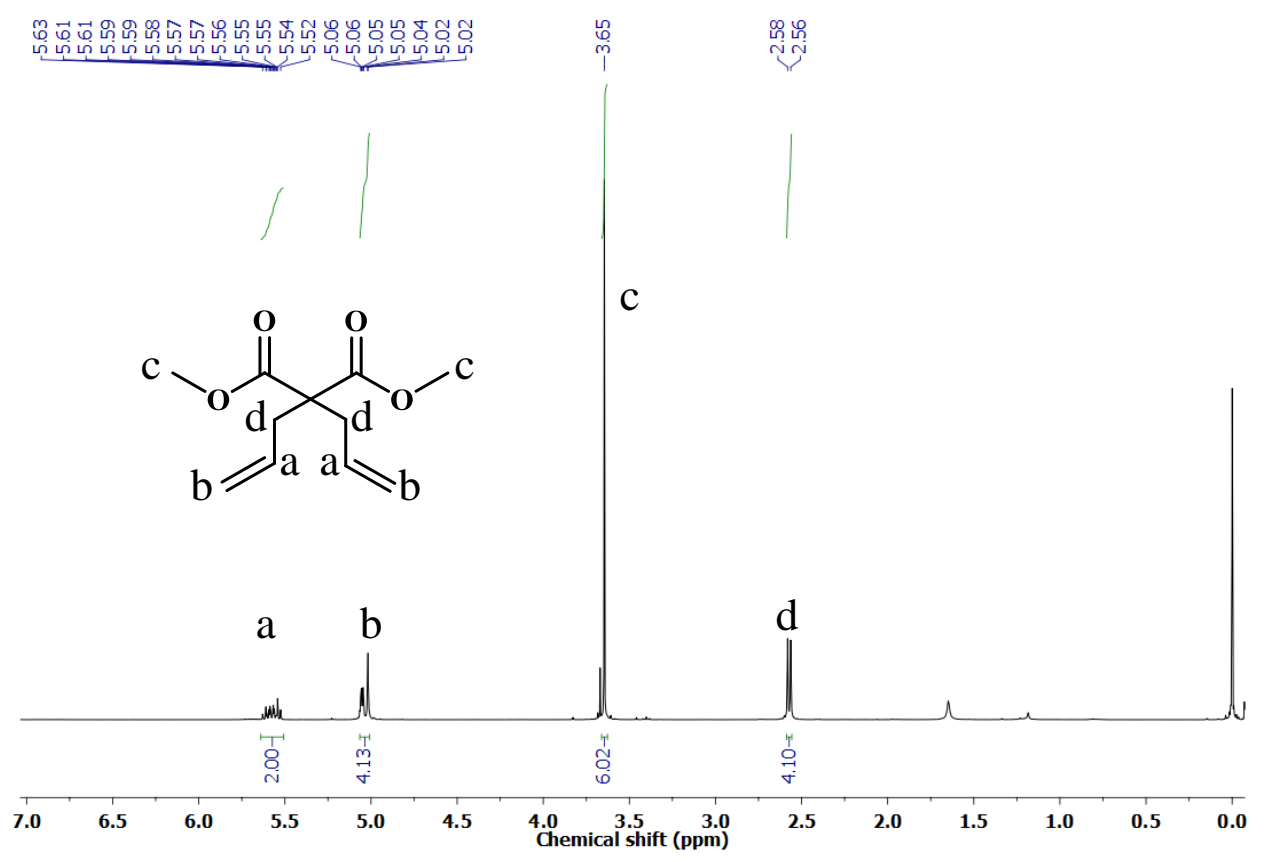

Figure S40. ${ }^{1} \mathrm{H}$ NMR spectrum of dimethyl 2,2-diallylmalonate (4c).

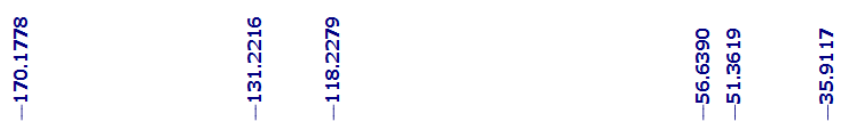<smiles>C=CCC(CC=C)(C(=O)OC)C(=O)OC</smiles>

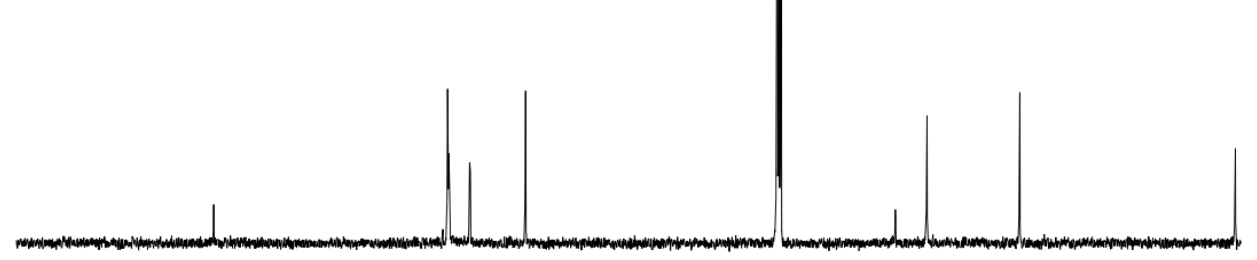

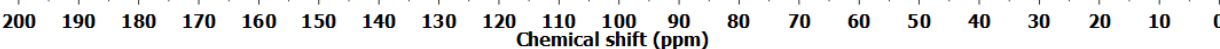

Figure S41. ${ }^{13} \mathrm{C}$ NMR spectrum of dimethyl 2,2-diallylmalonate (4c). 


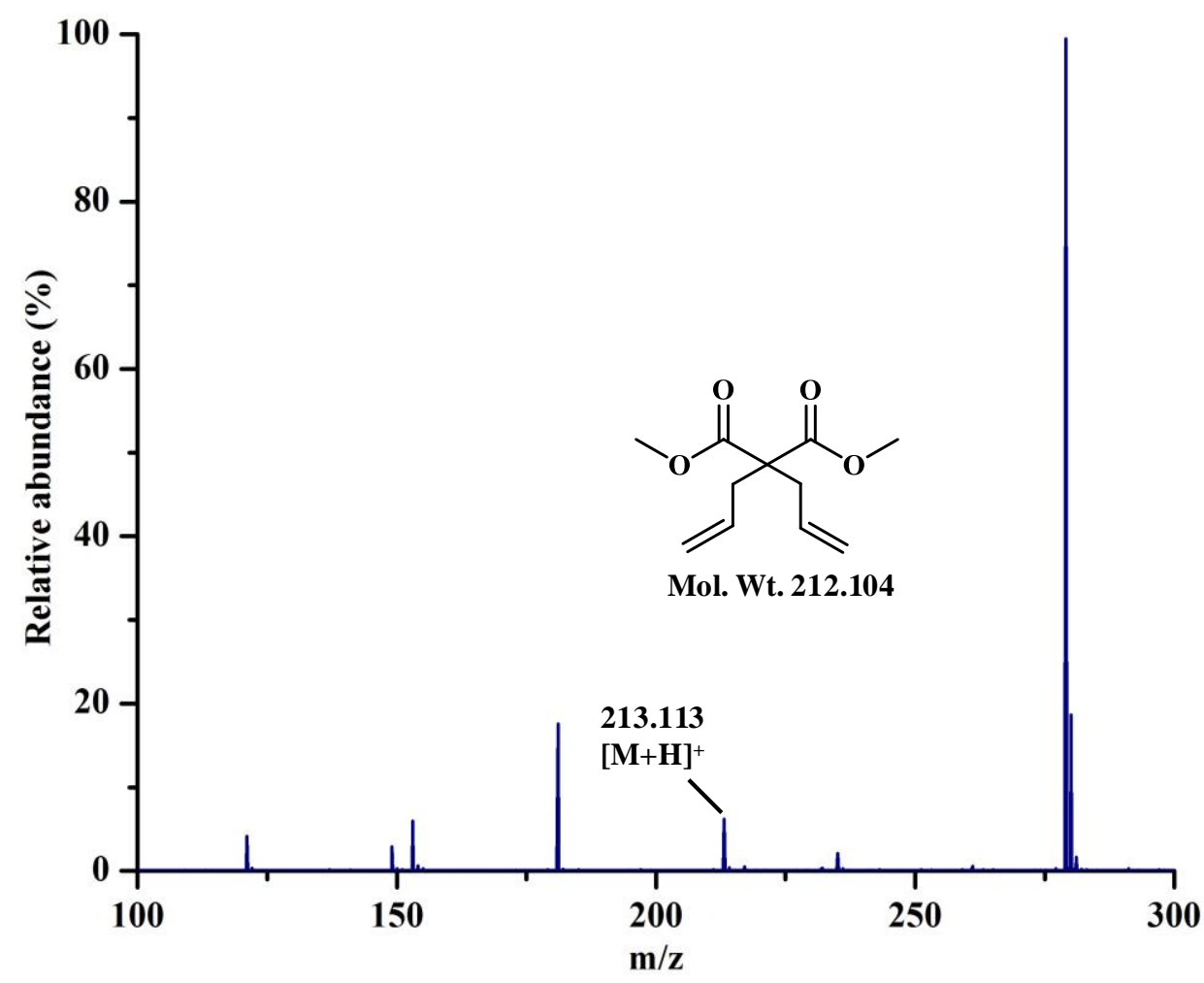

Figure S42. ESI-MS (positive mode) of dimethyl 2,2-diallylmalonate (4c).

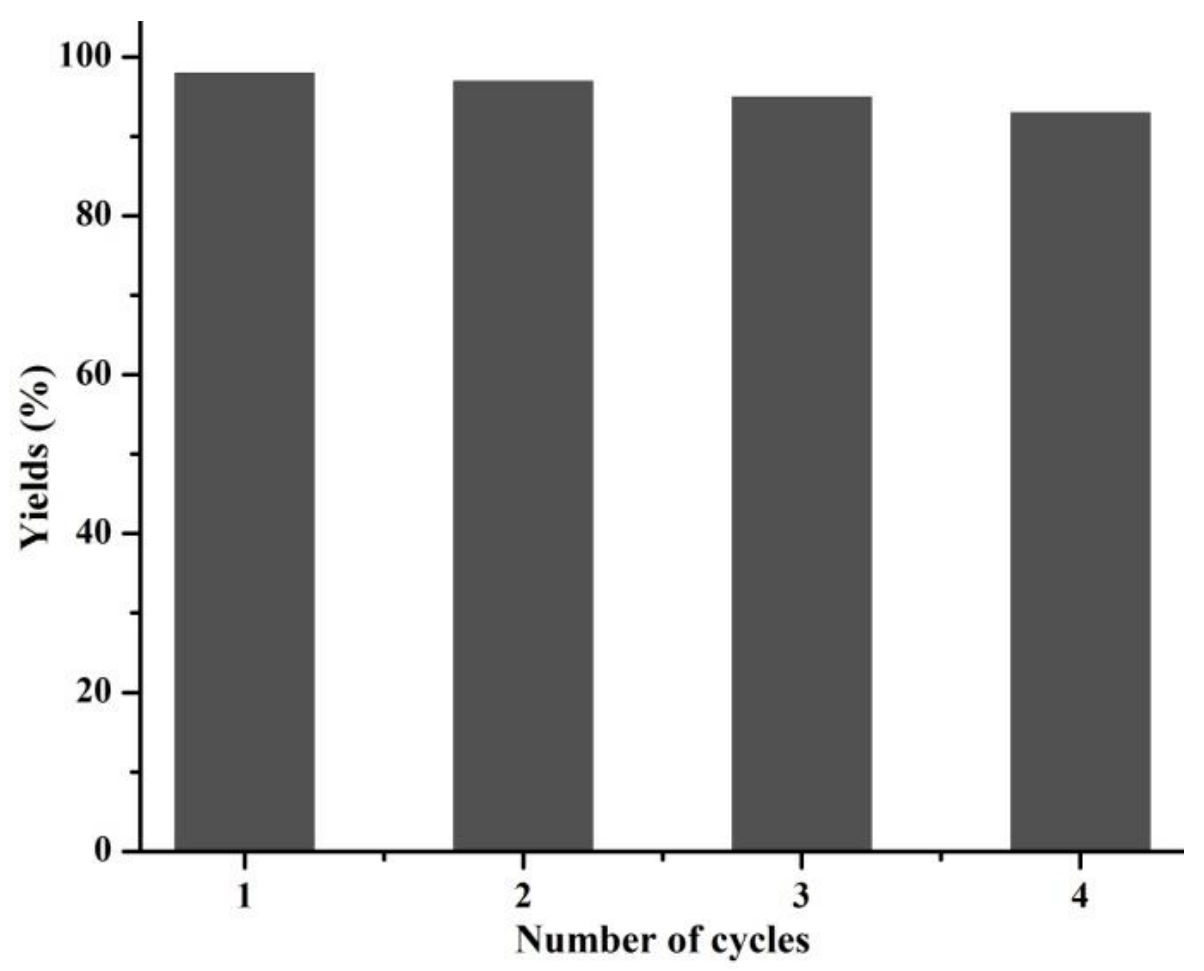

Figure S43. Recyclability of the Pd@o-OC catalysts. 


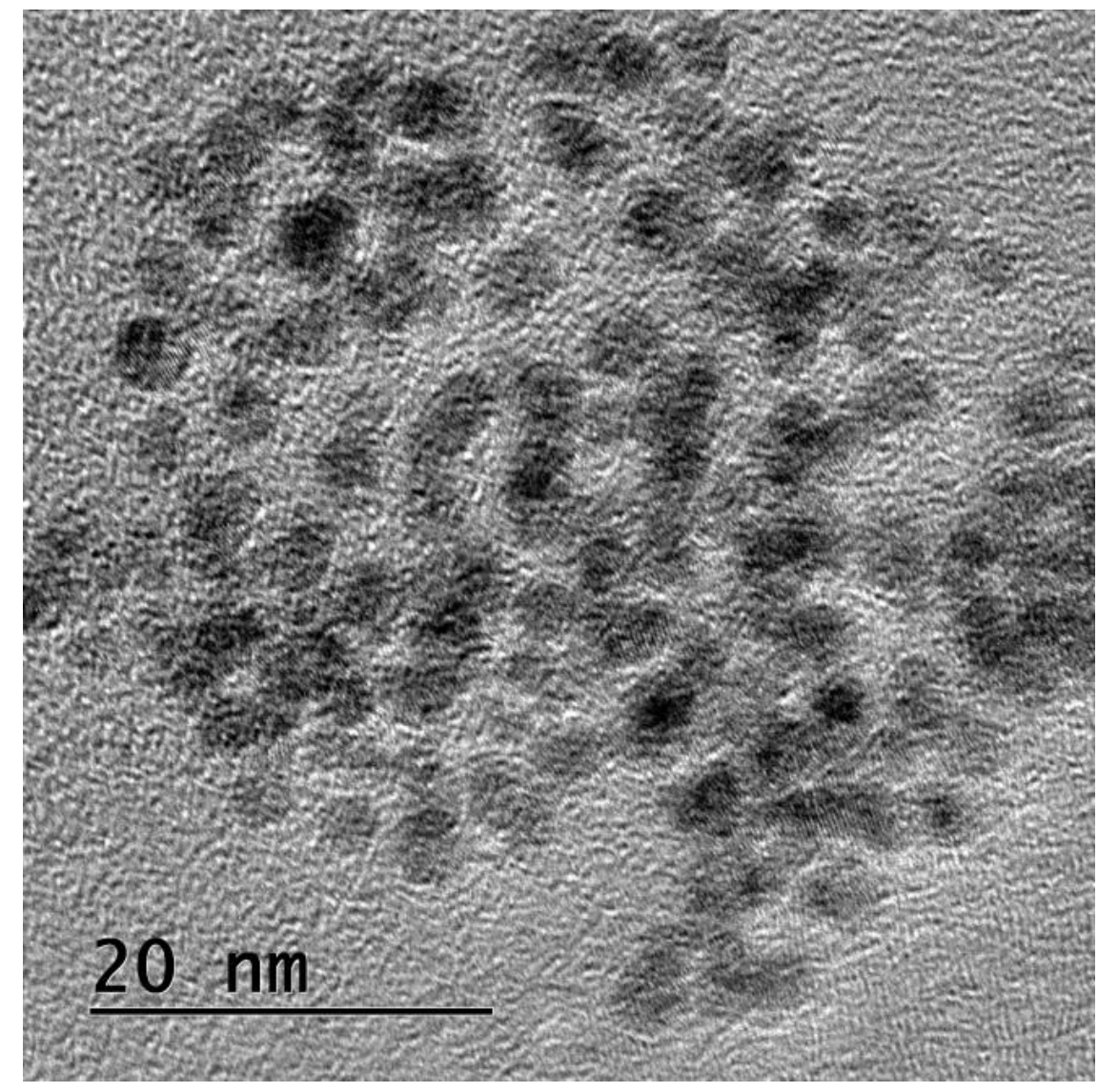

Figure S44. HRTEM image of Pd@o-OC after 4 cycles.

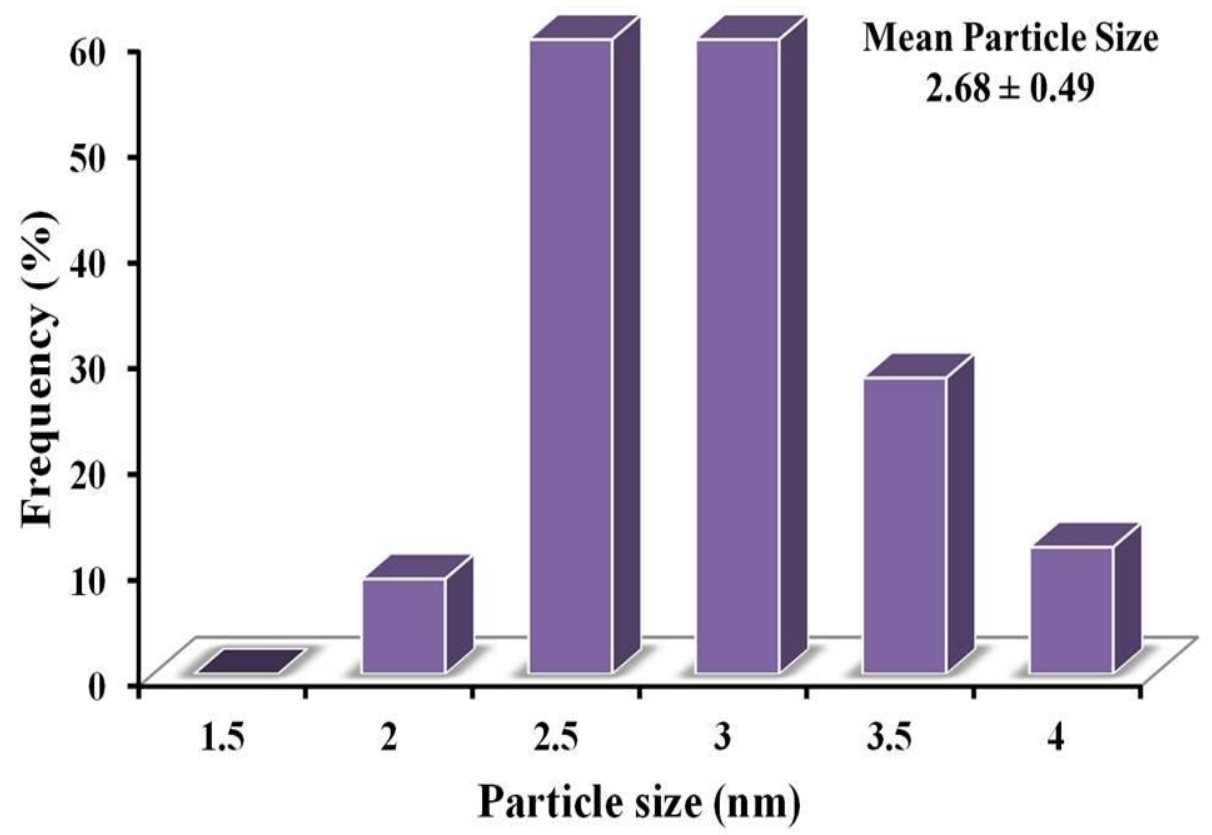

Figure S45. Particle size distribution of Pd@o-OC after 4 cycles. 


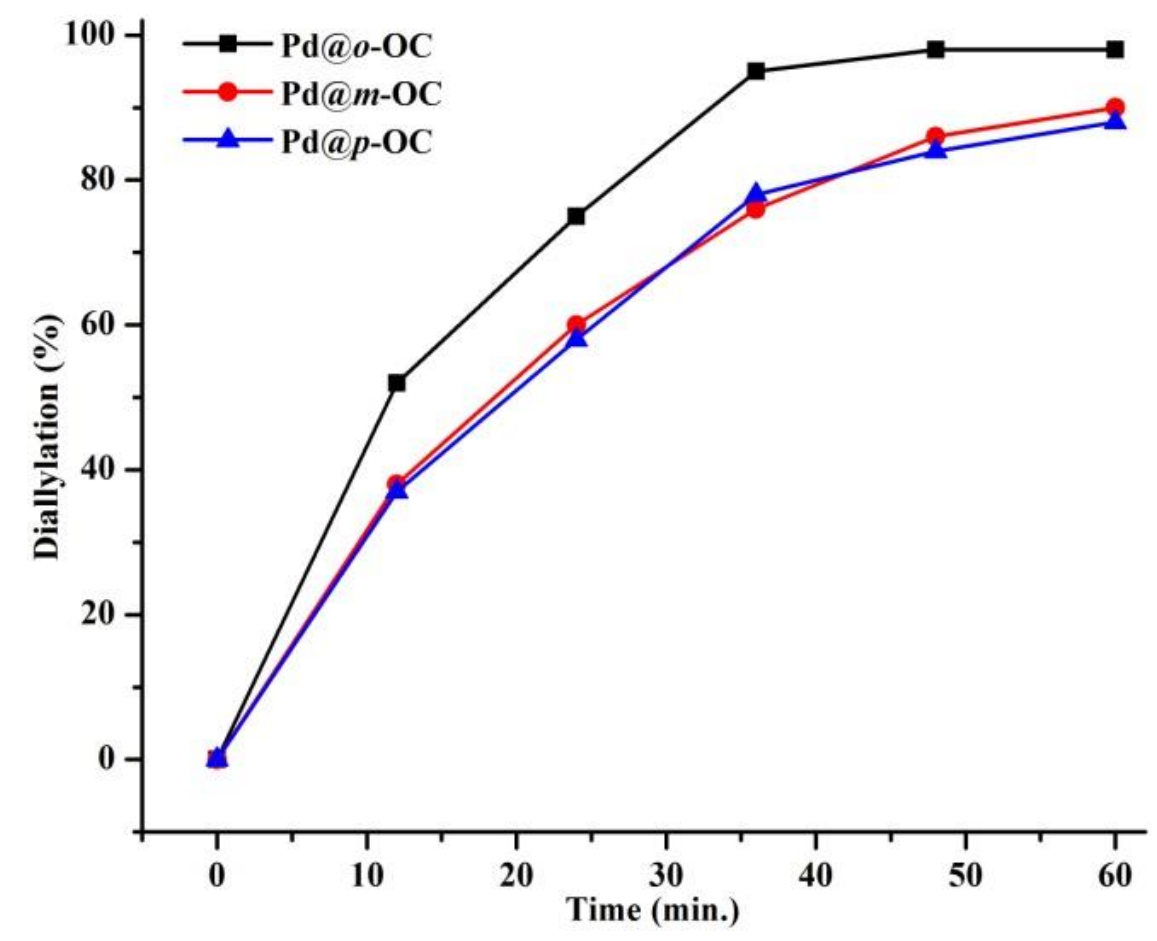

Figure S46. Rate of Diallylation of Ethyl Acetoacetate with each catalyst.

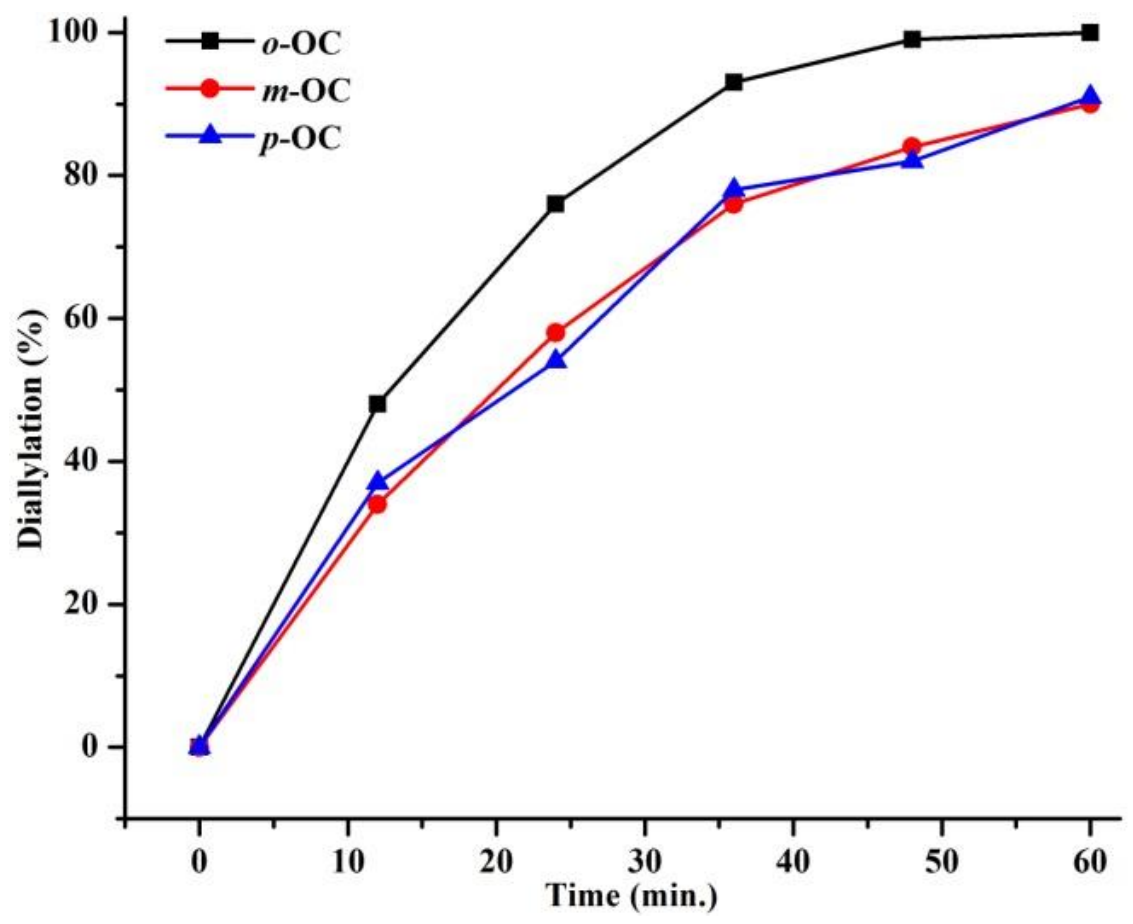

Figure S47. Rate of Diallylation of Acetyl Acetone with each catalyst. 


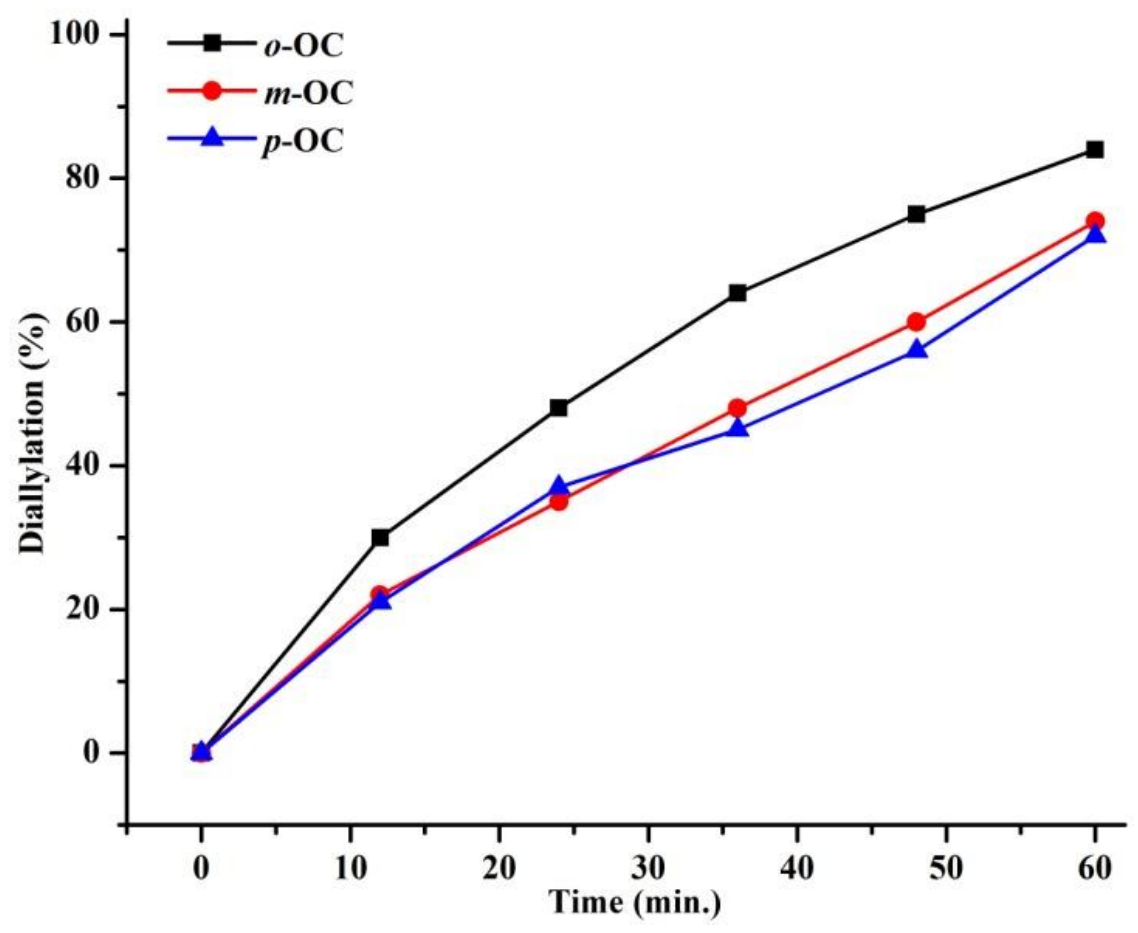

Figure S48. Rate of Diallylation of Dimethyl Malonate with each catalyst.

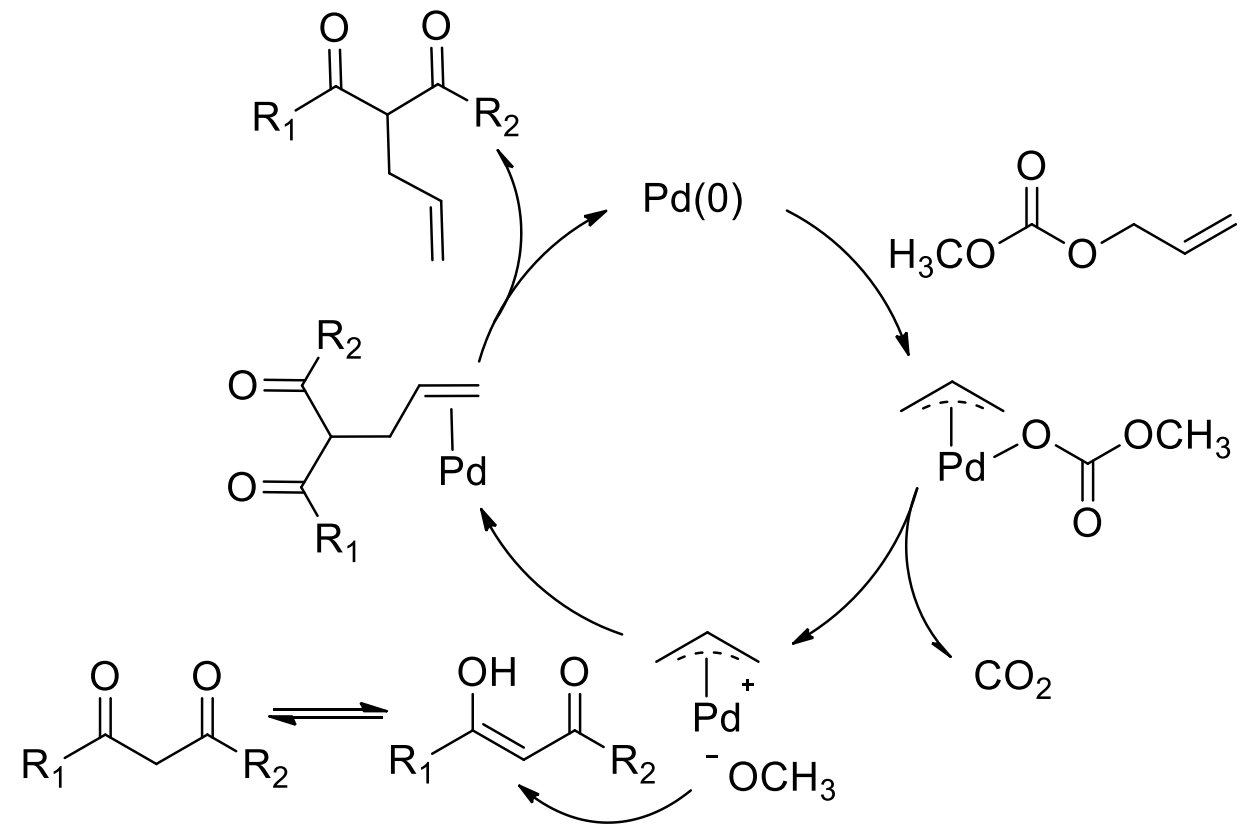

Scheme S1. Mechanism of allylation of active methylene compound. 


\section{References}

1. Becke, A. D. Density-Functional Thermochemistry. III. The Role of Exact Exchange. $J$. Chem. Phys. 1993, 98, 5648-5652.

2. Lee, C.; Yang, W.; Parr, R. G. Development of the Colle-Salvetti Correlation-energy formula into a functional of the electron density. Phys. Rev. B 1988, 37, 785-789.

3. Grimme, S.; Antony, Ehrlich, S.; Krieg, H. A consistent and accurate ab initio parametrization of density functional dispersion correction (DFT-D) for the 94 elements H-Pu. J. Chem. Phys. 2010, 132, 154104.

4. Hariharan, P. C.; Pople, J. A. The Influence of Polarization Functions on Molecular Orbital Hydrogenation Energies. Theoret. Chimica Acta 1973, 28, 213-222.

5. Gaussian 16, Revision B.01, Frisch, M. J.; Trucks, G. W.; Schlegel, H. B.; Scuseria, G. E.; Robb, M. A.; Cheeseman, J. R.; Scalmani, G.; Barone, V.; Petersson, G. A.; Nakatsuji, H.; Li, X.; Caricato, M.; Marenich, A. V.; Bloino, J.; Janesko, B. G.; Gomperts, R.; Mennucci, B.; Hratchian, H. P.; Ortiz, J. V.; Izmaylov, A. F.; Sonnenberg, J. L.; Williams-Young, D.; Ding, F.; Lipparini, F.; Egidi, F.; Goings, J.; Peng, B.; Petrone, A.; Henderson, T.; Ranasinghe, D.; Zakrzewski, V. G.; Gao, J.; Rega, N.; Zheng, G.; Liang, W.; Hada, M.; Ehara, M.; Toyota, K.; Fukuda, R.; Hasegawa, J.; Ishida, M.; Nakajima, T.; Honda, Y.; Kitao, O.; Nakai, H.; Vreven, T.; Throssell, K.; Montgomery, J. A., Jr.; Peralta, J. E.; Ogliaro, F.; Bearpark, M. J.; Heyd, J. J.; Brothers, E. N.; Kudin, K. N.; Staroverov, V. N.; Keith, T. A.; Kobayashi, R.; Normand, J.; Raghavachari, K.; Rendell, A. P.; Burant, J. C.; Iyengar, S. S.; Tomasi, J.; Cossi, M.; Millam, J. M.; Klene, M.; Adamo, C.; Cammi, R.; Ochterski, J. W.; Martin, R. L.; Morokuma, K.; Farkas, O.; Foresman, J. B.; Fox, D. J. Gaussian, Inc., Wallingford CT, 2016. 